OPEN ACCESS

Edited by:

Paul Takam Kamga,

Université de Versailles

Saint-Quentin-en-Yvelines, France

Reviewed by:

Jelena Stojsic,

University of Belgrade, Serbia

Loredana Urso,

University of Padua, Italy

${ }^{*}$ Correspondence:

Sarah Sayed Hassanein

sarah.hassanein@ejust.edu.eg; ssara@sci.cu.edu.eg

tORCID:

Sarah Sayed Hassanein

0000-0003-0545-4215

Ahmed L. Abdelmawgood 0000-0001-9784-1014

Sherif A. Ibrahim

0000-0001-6403-7345

${ }^{\ddagger}$ These authors have contributed equally to this work and share senior authorship

Specialty section:

This article was submitted to Thoracic Oncology.

a section of the journal

Frontiers in Oncology

Received: 29 August 2021 Accepted: 23 November 2021 Published: 15 December 2021

Citation:

Hassanein SS, Abdel-Mawgood AL and Ibrahim SA (2021) EGFRDependent Extracellular Matrix Protein Interactions Might Light a Candle in Cell Behavior of Non-Small Cell Lung Cancer.

Front. Oncol. 11:766659. doi: 10.3389/fonc.2021.766659

\section{EGFR-Dependent Extracellular Matrix Protein Interactions Might Light a Candle in Cell Behavior of Non-Small Cell Lung Cancer}

\author{
Sarah Sayed Hassanein ${ }^{1,2}{ }^{* \neq}$, Ahmed Lotfy Abdel-Mawgood ${ }^{1+\neq}$ \\ and Sherif Abdelaziz Ibrahim ${ }^{2 \dagger \neq}$

\begin{abstract}
${ }^{1}$ Biotechnology Program, Basic and Applied Sciences (BAS) Institute, Egypt-Japan University of Science and Technology
\end{abstract} \\ (E-JUST), Alexandria, Egypt, ${ }^{2}$ Zoology Department, Faculty of Science, Cairo University, Giza, Egypt
}

Lung cancer remains the leading cause of cancer-related death and is associated with a poor prognosis. Lung cancer is divided into 2 main types: the major in incidence is nonsmall cell lung cancer (NSCLC) and the minor is small cell lung cancer (SCLC). Although NSCLC progression depends on driver mutations, it is also affected by the extracellular matrix (ECM) interactions that activate their corresponding signaling molecules in concert with integrins and matrix metalloproteinases (MMPs). These signaling molecules include cytoplasmic kinases, small GTPases, adapter proteins, and receptor tyrosine kinases (RTKs), particularly the epidermal growth factor receptor (EGFR). In NSCLC, the interplay between ECM and EGFR regulates ECM stiffness, angiogenesis, survival, adhesion, migration, and metastasis. Furthermore, some tumor-promoting ECM components (e.g., glycoproteins and proteoglycans) enhance activation of EGFR and loss of PTEN. On the other hand, other tumor-suppressing glycoproteins and -proteoglycans can inhibit EGFR activation, suppressing cell invasion and migration. Therefore, deciphering the molecular mechanisms underlying EGFR and ECM interactions might provide a better understanding of disease pathobiology and aid in developing therapeutic strategies. This review critically discusses the crosstalk between EGFR and ECM affecting cell behavior of NSCLC, as well as the involvement of ECM components in developing resistance to EGFR inhibition.

Keywords: epidermal growth factor receptor (EGFR), extracellular matrix (ECM), non-small cell lung cancer (NSCLC), integrin receptors, proteoglycans, glycoproteins, matrix metalloproteinases (MMPs), tyrosine kinase inhibitors (TKIs).

\section{INTRODUCTION}

Globally, lung cancer is the foremost cause of cancer-related death, accounting for 2.09 million cases and 1.76 million deaths in 2018, according to GLOBOCAN (1). Two types of lung cancer are known: nonsmall cell lung cancer (NSCLC) and small cell lung cancer (SCLC), with an incidence rate of $85 \%$ and $14 \%$, respectively. According to histological characteristics, NSCLC is divided into lung adenocarcinoma (ADC), squamous cell carcinoma (SqCC), and large cell carcinoma (LCC) (2). Most likely, lung cancer is 
diagnosed at locally advanced or metastatic stages in $70 \%$ of patients, leading to a low 5-year survival rate (15\%) (3). Lung cancer metastasis is the primary cause of death in most patients, including metastasis to the brain (20-40\%), bones (30-40\%); however, the mechanism has yet remained unclear $(4,5)$. The latest advances in technology have helped determine genetic, epigenetic, and proteomic alterations in different cancers (6). The epidermal growth factor receptor (EGFR) signaling pathway plays a crucial role in NSCLC progression $(7,8)$.

The EGFR is a transmembrane glycoprotein receptor that belongs to the ErbB family of receptor tyrosine kinases (RTKs). There are four types of EGF receptors (HER1/EGFR/ErbB1, HER2/ ErbB2, HER3/ErbB3, and HER4/ErbB4) that comprise a cysteinerich extracellular ligand-binding domain (LBD), an $\alpha$-helix transmembrane domain (single-pass), a C-terminal domain, and except HER3, a cytoplasmic tyrosine kinase (TK) domain (8). The EGFR signaling pathway is multifaceted, with more than 13 extracellular ligands. Upon ligand-receptor binding, the dimerization of the receptor either with the same (homodimerization) or another receptor (heterodimerization) of the EGFR family takes place $(9,10)$. Upon EGFR dimerization, it activates one or more downstream cascades, including the phosphatidylinositol-3-kinase/protein kinase B (PI3K/AKT), mitogen-activated protein kinase (MAPK), extracellular signalregulated kinase (MEK/ERK), mammalian target of rapamycin (mTOR), and signal transducer and activator of transcription (STAT) pathways through autophosphorylation of the receptor as well as the cytoplasmic protein binding $(11,12)$. EGFR is normally downregulated after receptor activation by an endocytic pathway, resulting in receptor degradation or recycling. The uncontrolled EGFR pathway induces aberrant signaling linked with many airway illnesses, including extreme airway proliferation, hypersecretion, mucus overproduction, and advanced distal lung fibrosis and cancer $(13,14)$. Lung SqCC and ADC patients can harbor abnormal EGFR pathway activation and conserved ErbB1 gene mutations (15) that are approximately $90 \%$ in exons $18-21$ of its kinase domain, besides an additional 5\% denoted to an in-frame deletion in exons 2-7 (13). Tumor extracellular matrix (ECM) composition can play a role in EGFR-dependent lung cancers.

ECM is a significant part of all tissues' microenvironment. It offers physical support for the neighboring cells, binds growth factors, and controls cell behavior under physiological and pathological conditions (16). ECM is composed of a non-cellular network of proteins, proteoglycans, glycoproteins, and polysaccharides that constitute the interstitial matrix (IM) and the basement membrane (BM) (17). The latter is a well-structured membrane, underlining epithelial and endothelial cells under healthy conditions to separate them from the IM, which constitutes the main stroma and plays a significant role in cell adhesion, cell migration, tissue development, angiogenesis, and repair (18). It is well-known that carcinogenesis is multistep genetic and epigenetic variations, resulting in oncogenes overexpression and downregulation of tumor suppressor genes (19). These aberrations induce cancer cells to stimulate adjacent stromal cells and augment the release of ECM proteins, growth factors, cytokines, angiogenic factors, and proteolytic enzymes into tumor stroma to form a tumor-supportive microenvironment (Figure 1) $(20,21)$. The development of resistance to EGFR tyrosine kinase inhibitors (TKIs) is still a critical problem in lung cancer, and the underlying mechanisms remain fully unexplored (22). Although TKI-induced or -selected genetic alterations are known to cause chemoresistance, other poorly understood mechanisms in tumor cells can drive this resistance. In the absence of genetic alterations, ECM components are players in TKI resistance (23). In the following sections, we highlight the different types of ECM proteins and their roles in mediating EGFR signaling to pinpoint their significance in NSCLC as biomarkers for diagnosis and prognosis and their potential as druggable targets.

\section{ECM-KEY STRUCTURAL AND SIGNALING COMPONENTS MODULATE EGFR ACTIVATION AND AFFECT CELL BEHAVIOR OF NSCLC}

\subsection{Glycoproteins}

\subsubsection{Fibulins (FBLNs)}

Emerging data have indicated that the fibulin (FBLN) family comprising seven members (fibulin-1-7) of widely expressed ECM proteins is associated with lung cancer invasion and metastasis. FBLNs are ECM glycoproteins consisting of EGFlike domain repeats crucial for normal organogenesis and embryonic development (24). They are vital for these biological processes as they regulate cell-to-matrix communication and ECM structure stabilization through intermolecular bridges that bind to several supramolecular structures $(25,26)$. Besides their structural role, FBLNs are linked to many cellular signaling events and complex biologic processes, including cellular proliferation, adhesion, and migration $(25,27)$.

Fibulin-1 (FBLN1) expression levels are substantially downregulated in NSCLC (28). The role of FBLNs in regulating the EGFR function is shown in Figure 2. Harikrishnan et al. used siRNA to knock down FBLN1C and FBLN1D expression in NSCLC Calu-1 cells to examine if FBLN1 isoforms could play a role in controlling EGFR signaling and function (28). Without affecting overall EGFR expression levels, FBLN1C and FBLN1D expression loss significantly increases basal (with serum) and EGF-mediated EGFR activation. Conversely, overexpression of FBLN1D and FBLN1C inhibits EGFR activation, indicating a regulatory crosstalk between the two proteins.

FBLN3's functions and signaling mechanisms in lung cancer stem cells (CSCs) were investigated (29). Moreover, FBLN3 was downregulated in the lung (30) and nasopharyngeal carcinomas (31). Forced expression of FBLN3 reduces the expression of epithelial-mesenchymal transition (EMT) activators, including $\mathrm{N}$-cadherin and Snail, which inhibit ADC cell invasion and migration. FBLN3 inhibits the stemness activities of ADC cells, as shown by a decline in spheroid formation and the levels of stemness markers, including SRY-like HMG box (Sox2) and $\beta$ catenin. FBLN3 effects are mediated by the glycogen synthase 


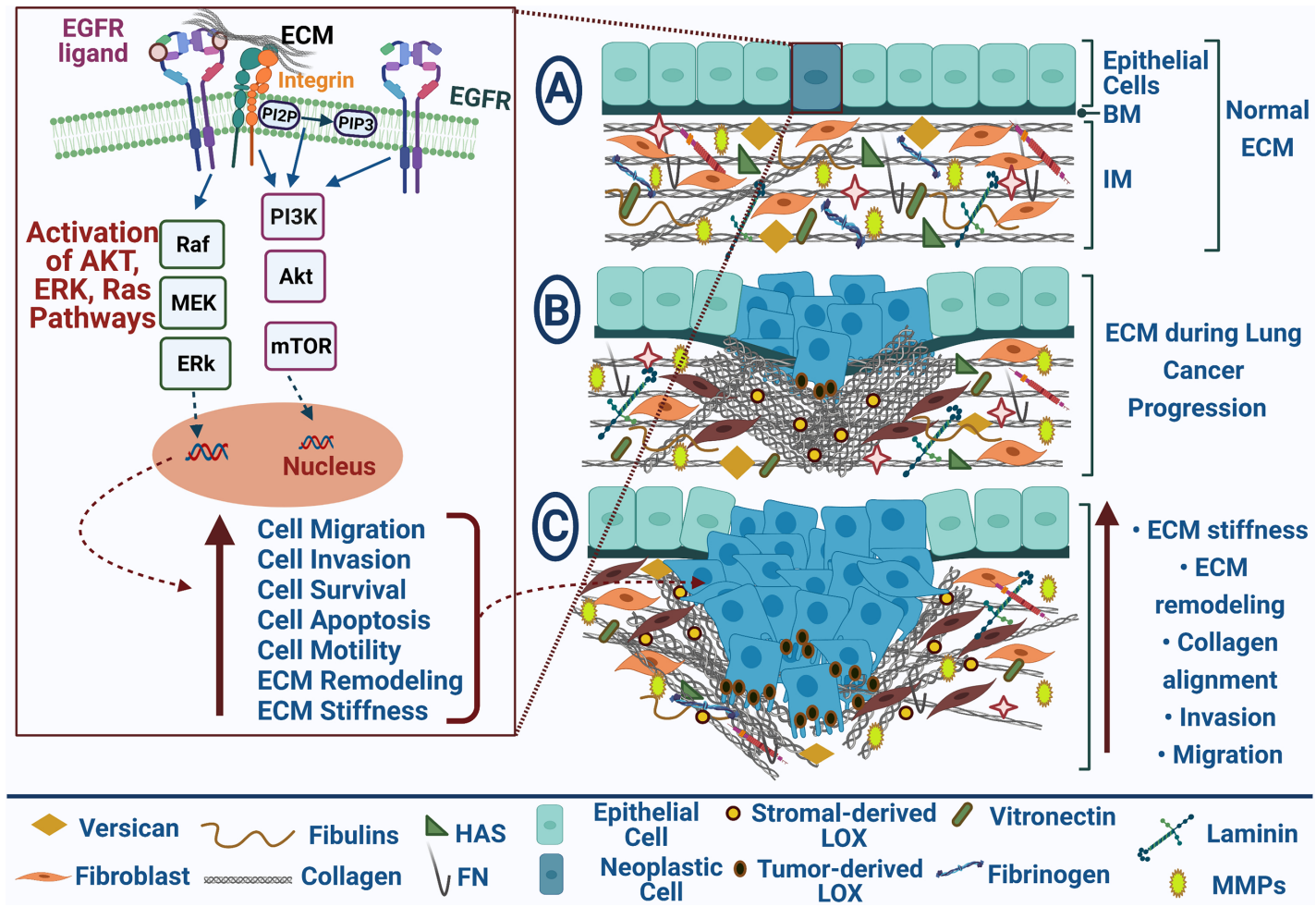

FIGURE 1 | EGFR-mediated ECM remodeling during lung cancer progression. EGFR and ECM receptors, integrins, results in Akt, Erk, and Ras pathways' activation that participate in increasing cell migration, invasion, survival, and motility and repressing cell apoptosis; (A) Normal ECM in healthy tissue; (B) Neoplastic cells with uncontrolled cell growth promote ECM remodeling during lung cancer progression; (C) Tumor migration and invasion are mediated by collagen alignment and ECM stiffness. Blue arrows point to stimulation, upright-directed red arrows point to increase effect, and dashed red arrows point to cellular effect.

kinase-3 $\beta($ GSK3 $\beta) / \beta$-catenin pathway and the upstream regulators of GSK3 $\beta$ such as (PI3K)/AKT and insulin-like growth factor receptor (IGF1R). Furthermore, IGF1R was discovered to be a direct target of FBLN3, which inhibits the action of IGF. Further, FBLN3 inhibits lung CSC and EMT by modulating the IGF1R/PI3K/AKT/GSK3 pathway, and that FBLN3 may be used as a CSC-centered therapeutic alternative (29). FBLN3 could attenuate the invasion of NSCLC A549 cells by inhibiting the transcription of matrix metalloproteinase(MMP)-7 and MMP-2 (32). Again, Chen et al. revealed the function of FBLN3 and FBLN5 as suppressors of lung cancer invasion and metastasis through the inhibition of Wnt/ $\beta$-catenin and ERK signaling pathways (33) that, in turn, downregulate MMP-2 and MMP-7 expression (32) and inhibit lung cancer cell survival, proliferation, and metastasis $(34,35)$. Moreover, FBLN3 overexpression notably decreased the activities of MMP-2 and MMP-9 and repressed the invasion of NSCLC A549 cells; thus, it could be used as a therapeutic strategy for NSCLC (36).

FBLN5 (DANCE), a vascular integrin receptor ligand, is a distinct member of fibulins harboring the RGD (Arg-Gly-Asp) motif associated with endothelial cell adhesion (37). FBLN5 can also depend on RGD to attenuate angiogenesis (38). It interacts directly with elastic fibers in vitro, and its amino-terminal domain serves as a ligand for cell surface integrins $\alpha v \beta 3, \alpha 9 \beta 1$, and $\alpha v \beta 5$ (39-41). FBLN5 expression is induced under pathological conditions, including pulmonary hypertension and lung injury (42), and is controlled by transforming growth factor- $\beta$ (TGF- $\beta$ ) (43). FBLN5 was discovered to be a suppressor of lung cancer invasion and metastasis via inhibiting MMP-7. Indeed, FBLN5 knockdown induces cell invasion and MMP-7 expression. In lung tumors, the expression levels of FBLN5 and MMP-7 are inversely associated. FBLN5 suppresses MMP-7 expression through the ERK pathway, which is mediated by an integrin-binding RGD motif. FBLN5 overexpression in H460 lung cancer cells also prevents metastasis in mice. These findings indicate that epigenetically silenced FBLN5 promotes lung cancer invasion and metastasis by inducing MMP-7 expression through the ERK pathway (44).

\subsubsection{Mucins}

Mucins (MUCs) are high M.wt glycoproteins synthesized by many epithelial tissues (45). They are categorized into two major groups: secretory mucins and membrane-bound mucins. There are 11 membrane-bound mucins (MUC1, MUC3A, MUC3B, MUC4, MUC12, MUC13, MUC15, MUC16, MUC17, MUC20, and MUC21) and seven secreted mucins (MUC2, MUC5AC, MUC5B, MUC6, MUC7, MUC8, and MUC19) (46). MUCs are involved in the normal development of the lungs and are 

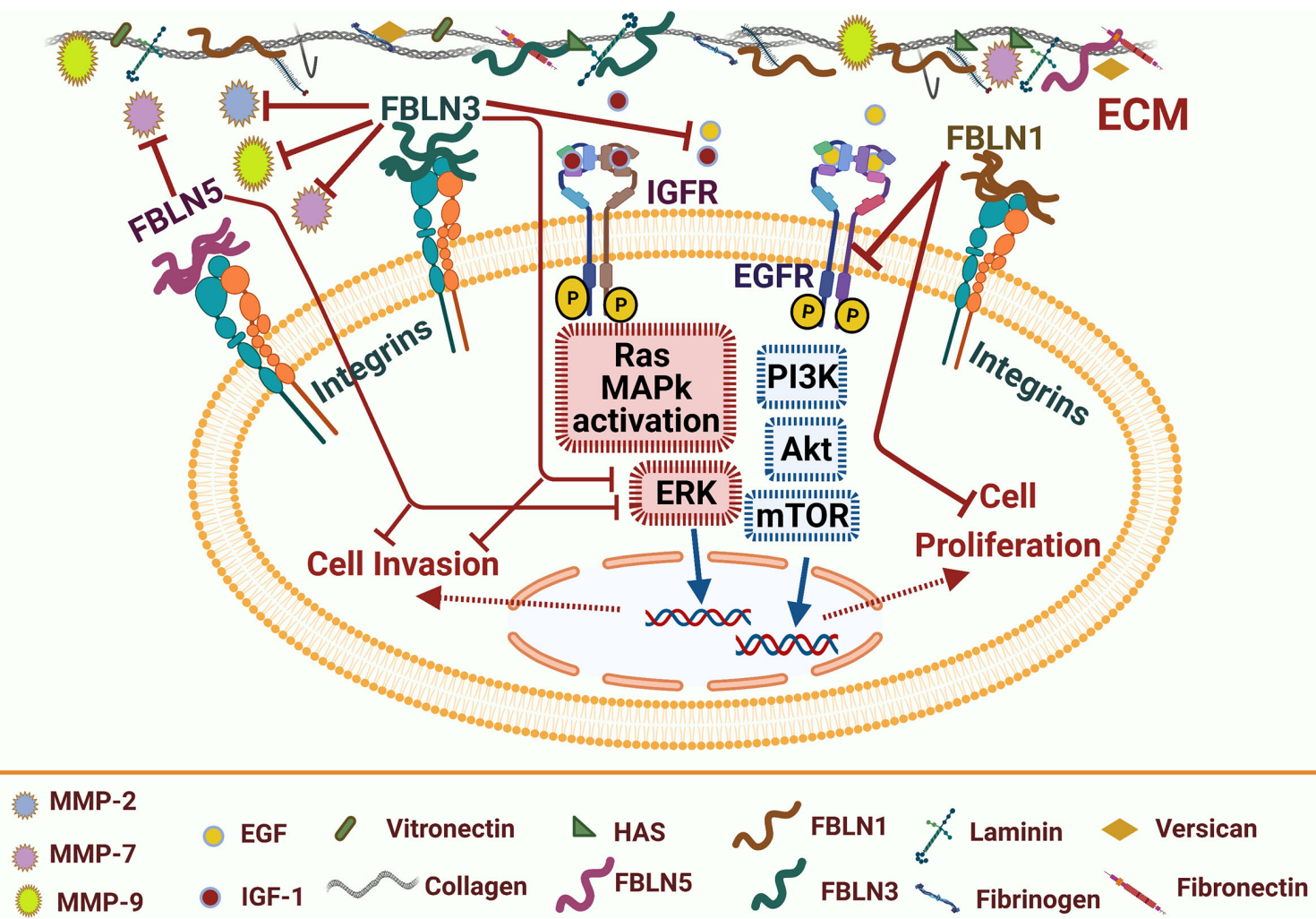

FIGURE 2 | Fibulins-mediated EGFR signaling pathways and matrix metalloproteinases in lung cancer. Fibulin (FBLN) family includes many types such as FBLN1,3\&5 serve as tumor-suppressor proteoglycans. FBLN1 can inhibit EGFR activation and thus suppress cell proliferation. FBLN3 can compete with EGF and IGF-1 binding to their receptors; it also can inhibit transcription of oncogenic matrix metalloproteinases (MMP2\& MMP9). FBLN3/5 can inhibit MMP7 and Erk pathway activation and thus inhibit cell invasion. Blue arrows for stimulation; dashed red arrows for cellular effect, and red "T" sign for inhibition.

expressed during the embryonic stages of lung development. The cytoplasmic domain of MUC1-C contains i) a YEKV motif: a substrate for EGFR phosphorylation and a SRC SH2 binding site (47), ii) a YHPM motif: a binding site for PI3K and the AKT pathway activation $(48,49)$, and iii) a YTNP motif: Upon tyrosine phosphorylation, it interacts with Grb2, which binds MUC1-C to son of sevenless (SOS) and thereby activating the $\mathrm{RAS} \rightarrow \mathrm{MEK} \rightarrow$ ERK pathway (49).

MUC1 is an oncogenic glycoprotein that binds to EGFR, serving as a substrate, and that MUC1 expression can enhance EGFR-dependent signaling. MUC1 expression can prevent degradation of EGFR in breast epithelial cells using overexpression constructs and RNAi-mediated knockdown of MUC1, increasing total cellular pools of EGFR (50). The MAPS (MUC1-associated proliferation signature) includes a cytoplasmic domain of MUC1 (MUC1-CD)-dependent genes, including cyclin B1 (CCNB1), cyclin-dependent kinase inhibitor 3 (CDKN3), cell division cycle protein $(C D C 2, C D C 20)$, mitotic arrest deficient 2-like protein 1 (MAD2L1), protein regulator of cytokinesis 1 (PRC1), and ribonucleoside-diphosphate reductase subunit M2 (RRM2), which are involved in cell cycle and proliferation regulation and have been linked to poor outcomes in patients with lung adenocarcinoma (51). MUC1 is expressed as MUC1-N and MUC1-C, a non-covalent heterodimer of $\mathrm{N}$-terminal and $\mathrm{C}$-terminal subunits, respectively (46). MUC1 overexpression, in association with MUC1-C, contributes to activation of the nuclear factor Kappa-activated B cells (NF- $\mathrm{KB})(52), \mathrm{Wnt} / \beta$-catenin/TCF4 (transcription factor 4) (53), and STAT1/3 pathways in NSCLC (54). In NSCLC, the heterodimeric protein MUC1 is abnormally overexpressed, resulting in gene signatures linked to poor patient survival (48). The cytoplasmic domain of MUC1-C is associated with PI3K p85 in NSCLC cells.

Blocking the interaction of MUC1-C with PI3K p85 via cellpenetrating peptides suppresses Akt phosphorylation and its downstream effector mTOR. Treatment of NSCLC cells with GO-203, a MUC1-C peptide inhibitor, results in downregulation of PI3K-Akt signaling, growth inhibition, an increase in reactive oxygen species (ROS), and necrosis induction via a ROSdependent mechanism. Furthermore, in H1975 (EGFR L858R/ T790M) mutant cells and A549 (K-Ras G12S) xenografts developed in nude mice after treatment with GO-203, tumor regressions were observed. These data suggest that MUC1-C is needed for PI3K-Akt pathway activation and survival in NSCLC cells (48). Galectin-3 is a $\beta$-galactoside binding protein that has also been linked to human cancer development. Glycosylation of 
the C-terminal subunit of Asn-36 is necessary for galectin-3 upregulation. Two Sentences have been transferred to section no. 8. Galectin-3 binds to MUC1-C at the glycosylated Asn-36 site. Galectin-3 acts as a bridge between EGFR and MUC1, besides galectin-3 is needed for EGF-mediated interactions between MUC1 and EGFR that support the importance of the MUC1C-galectin-3 interaction (55).

In EGFR mutant NSCLC, MUC5B-positive patients had significantly longer overall survival and relapse-free survival than MUC5B-negative patients. MUC5B appears to be a novel prognostic biomarker in NSCLC patients with EGFR mutations (56). Lung ADC subtypes, including invasive mucinous adenocarcinoma (IMA) and lepidic predominant adenocarcinoma (LPA) are associated with MUC expression. In this regard, MUC1 is expressed in LPA, whereas MUC5B, MUC5AC and MUC6 are expressed in IMA (57). Also, EGFR and KRAS (Kirsten Rat Sarcoma viral oncogene homolog) mutations and $\mathrm{Hnf} 4 \alpha$ expression may participate in mucin expression profiles in these lung ADC subtypes (57). The overexpression of MUC21 proteins with a particular glycosylation state is implicated in developing EGFR-mutated lung ADCs associated with a high frequency of lymphatic vessels invasion and lymph node metastasis (58). Additionally, MUC5AC is linked to poor prognosis and would be a prospective therapeutic target in lung ADC due to its role in enhancing tumor heterogeneity with mucin production (59). Therefore, developing treatment strategies targeting MUCs' expression and functions to manage NSCLC progression are under investigation (60).

\subsubsection{Fibronectin}

Fibronectin (FN) is present in multiple isoforms through alternative splicing, where 20 isoforms in humans have been discovered (61) and are involved in mediating many cellular interactions with the ECM (62). It is primarily synthesized by CAFs and polymerized into ECM fibrils that act as scaffolds for ECM binding molecules such as growth factors and cell surface receptors (63). FN is overexpressed in the stroma of NSCLC and can promote cancer cell adhesion, growth, differentiation, migration, invasion, survival, and resistance to chemotherapy (64). FN-dependent molecular pathways can control the tumor cell response to the stromal matrix and represent potential targets for managing chemo-resistant tumors (65). FNIII-1c, a peptide mimetic, can activate Toll-like receptors (TLRs) to promote NF- $\kappa \mathrm{B}$ activation and release inflammatory cytokine in fibroblasts (Figure 3) $(66,67)$. Notably, the PI3K/Akt pathway is the main pathway by which most cytokines and growth factors activate mTOR and its downstream targets. In NSCLC H1838 and $\mathrm{H} 1792$ cells, FN induces phosphorylation of eukaryotic initiation factor 4E-binding protein 1 (4E-BP1) and p70S6K1 (two downstream targets of mTOR), and Akt phosphorylation (an upstream inducer of mTOR), whereas it inhibits the tumor suppressor protein phosphatase that antagonizes the PI3K/Akt signal (68). Furthermore, FN inhibits liver kinase B1 (LKB1) mRNA and protein expression, as well as the phosphorylation of AMP-activated protein kinase (AMPK), both of which are known to inhibit mTOR. These data indicate that NSCLC cell proliferation induced by $\mathrm{FN}$ is mediated by Akt/mTOR/p70S6K pathway activation and LKB1/AMPK signaling inhibition (68).

\subsubsection{Laminin}

Laminins (Lns) are heterotrimeric extracellular glycoproteins found in all BMs. So far, more than $17 \mathrm{Ln}$ isoforms have been identified with a cross-shaped and specific arrangement of $\alpha, \beta$, and $\gamma$ subunits (69). Ln-332 and Ln5 consist of heterogeneous $\alpha 3, \beta 3$, and $\gamma 2$ chains and serve as BMs' essential structural constituent. Ln5 plays a crucial role in cellular migration and tumor invasion $(70,71)$. NSCLC patients with positive Ln5 expression had a slightly lower survival rate than Ln5-negative expression counterparts. Besides, positive Ln5 expression combined with the loss of PTEN, positive active EGFR expression, or positive active Akt expression has a significantly different overall survival. According to Cox regression analysis, the co-expression of Ln5, PTEN, and p-Akt are the three most independent prognostic markers in NSCLC patients. The findings illustrate the intricate tumorigenesis relationship between key signaling pathway molecules and ECM proteins (71) (Figure 3). A Ln receptor, namely integrin $\alpha 6 \beta 4$, triggers carcinoma progression through cooperation with various GFRs to facilitate invasion and metastasis (72). Using a lung cancer tissue microarray and immunohistochemistry (IHC), Stewart et al. discovered that SqCC has a higher integrin $\beta 4$ (ITGB4) expression than $\mathrm{ADC}$, and these data were verified in external gene expression data sets. Overexpression of ITGB4 is also linked to venous invasion and a lower overall patient survival rate. The most highly 50 altered genes related to ITGB4 identified in SqCC were Lns, CD151, collagens, $P I 3 K$, and EGFR-associated pathway genes, other recognized signaling partners using cBioPortal. Finally, they show that ITGB4 is overexpressed in NSCLC and is an unfavorable prognostic factor (72). Overall, these data suggest a potential correlation between Lns and EGFR in lung cancer prognosis; however, further studies are still required to profile expression patterns of different Ln types in NSCLC to underscore their clinical relevance.

\subsubsection{Fibrinogen}

Fibrinogen is a $350 \mathrm{kDa}$ glycoprotein synthesized mainly by the liver epithelium (73). It comprises two similar sets of three polypeptide chains, including $A \alpha, B \beta$, and $\gamma$, linked by five symmetrical disulfide bridges (74). Many proteins and cytokines such as vascular endothelial growth factor (VEGF) and fibroblast growth factor-2 (FGF-2) bind to fibrinogen affecting its biological behavior $(75,76)$. Lungs produce fibrinogen by inflammatory stimuli (77). Fibrinogen changed into insoluble fibrin via activated thrombin considerably affects blood clotting, inflammatory response, wound healing, fibrinolysis and neoplasia. Increased fibrinogen activity considerably affects cancer cell growth, progression, and metastasis (78).

Accumulating evidence indicates a correlation between fibrinogen and EGFR in lung cancer (79-81). A study by Shang et al. discovered a novel serum protein, fibrinogen alpha chain isoform 2 (FGA2), in lung ADC patients with mutated EGFR using microarray data analysis of 41,472 antibodies coupled with mass spectrometry analysis (79). Further, plasma 


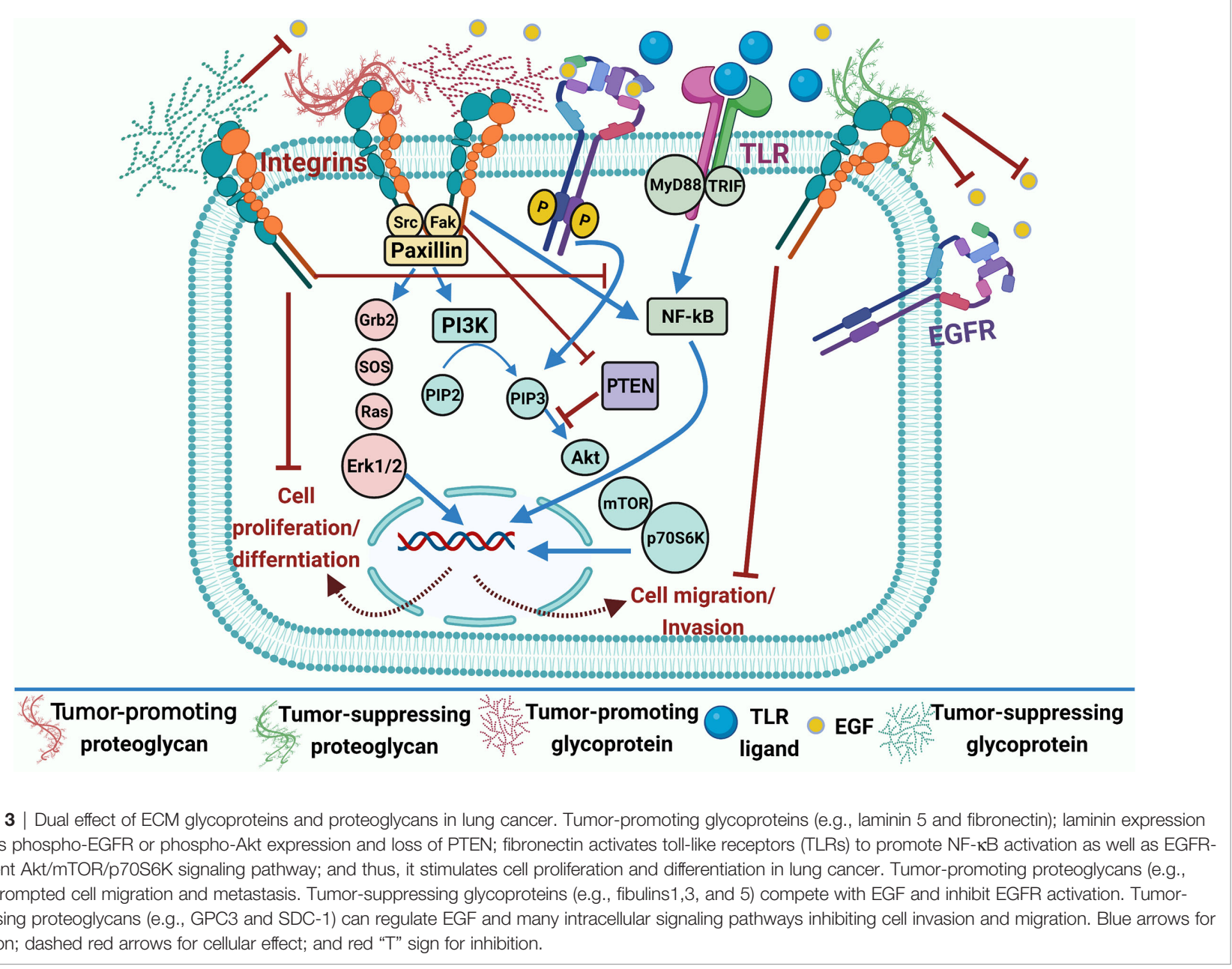

FGA2 levels were remarkably downregulated in EGFR-mutated patients relative to those with the wild-type EGFR (81). In the same study, hyperfibrinogenemia was linked to distant metastasis and lymphatic tissue metastasis. A multivariate model based on fibrinogen and smoking history was also used to predict EGFR mutation status in NSCLC patients (81). Furthermore, Fibrinogen-like protein 1 (FGL1) is significantly overexpressed in the gefitinib-resistant NSCLC cell line PC9/GR more than in the gefitinib-sensitive NSCLC cell line PC9 with an EGFR mutation. However, FGL1 knockdown reduces cell viability, decreases gefitinib IC50, and increases apoptosis in PC9/GR and PC9 cells after gefitinib therapy. FGL1 knockdown in PC9/GR tumor cells increases gefitinib's inhibitory and apoptosis-inducing effects in a mouse xenograft model. Gefitinib's possible mechanism for inducing apoptosis in PC9/ GR cells includes suppressing FGL1 and activating Poly (ADPRibose) Polymerase 1 (PARP1) and caspase 3 pathways. By regulating the PARP1/caspase 3 pathway, FGL1 promotes acquired resistance to gefitinib in the PC9/GR NSCLC cell line. As a result, FGL1 may be a possible therapeutic option for NSCLC patients who have developed resistance to gefitinib (80).

\subsubsection{Other ECM Glycoproteins}

Tenascin-C (TN-C) is a glycoprotein composed of 4 distinct domains interacting with matrix constituents, cell surface proteins, soluble factors, and pathogenic components. TN-C affects pulmonic blood vessel invasions by decreasing apoptosis and promoting cancer cell plasticity, thus, increasing lung metastasis (82). TN-C also binds to more than 25 different molecules, including EGF-L repeats (a low-affinity ligand for the EGFR, MAPK, and phospholipase-C gamma (PLC)- $\gamma$ signaling). Besides, TN-C binds to FNIII, aggrecan, integrins, and perlecan, along with growth factors such as FGF, plateletderived growth factor (PDGF), and TGF- $\beta$ families (83). Again, receptor-type tyrosine-protein phosphatase zeta (PTPR $\zeta 1$ ), fibrinogen-like globe (FBG) that can bind to integrins, and TLR4 are TN-C-related molecules (83). These diverse interactions render TN-C a significant driver for many processes such as cell attachment, cell migration, cell spreading, cell survival, focal adhesion, neurite outgrowth, protease, and matrix assembly, and pro-inflammatory cytokine synthesis (83). However, a correlation between TN-C and EGFR has not yet been elucidated in NSCLC. 
Periostin (Postn, PN, or osteoblast-specific factor OSF-2) is a vital ECM protein known for its complex role in tumorigenesis (84). It can directly bind to many ECM proteins, including TNC, FN, collagen, and Postn itself (85). Also, it acts as a ligand for numerous integrins such as $\alpha_{v} \beta_{3}, \alpha_{v} \beta_{5}$, and $\alpha_{6} \beta_{4}$ to participate in cell adhesion, survival, and migration $(85,86)$. Postn affects tumor progression by regulating cellular survival, angiogenesis, invasion, and metastasis in epithelial tumors (85). Periostin is overexpressed and enhances metastatic growth in colon cancer by inhibiting stress-induced apoptosis in cancer cells and increasing endothelial cell survival to boost angiogenesis. Although there is no direct association between Postn and EGFR in lung cancer, Postn can regulate EGFR interacting partners or its downstream signaling. Periostin increases cellular survival at the molecular level by activating the Akt/ PKB signaling pathway through $\alpha_{v} \beta_{3}$ integrins (87). In lung cancer, high Postn expression is positively associated with the EMT markers Snail and Twist and lung cancer stage, according to IHC results. Further, recombinant Postn causes EMT in lung cancer cells through the p38/ERK pathway, and that pretreatment with chemical inhibitors prevents Postn-induced EMT (88). Moreover, the increased Postn expression in the NSCLC A549 cells is one form of cellular response to chemical-mimic hypoxia stress, and this effect can be controlled by hypoxia-inducible growth factors like TGF- $\alpha$ and bFGF, which trigger the RTK/PI3-K pathway leading to upregulation of Postn, and in turn, facilitating the survival of A549 cells in a hypoxic microenvironment via the Akt/PKB pathway (89). Collectively, these data indicate that Postn may serve as a therapeutic target in NSCLC.

Vitronectin (VTN) is a multifunctional glycoprotein found in blood and ECM. It binds collagen, glycosaminoglycans, the urokinase-receptor, and plasminogen and stabilizes plasminogen activation inhibitor-1 (PAI-1)'s inhibitory conformation. VTN can potentially control the ECM proteolytic degradation through its localization in the ECM and binding to PAI-1. VTN also binds to complement, heparin, and thrombin-antithrombin III complexes, suggesting an immune response role and clot formation control (90). VTN is mostly overexpressed in smaller and well-differentiated tumors (91). EGF promotes carcinoma cell metastasis by phosphorylating p130 CAS in an Src-dependent manner, activating Ras-related protein 1 (Rap1), a small GTPase implicated in integrin activation. Src activity induced by EGFR causes phosphorylation of the CAS substrate, required for Rap1 and $\alpha v \beta 5$ activation (92). EGFR activation of Src initiates $\alpha v \beta 5$ mediated migration in FG (express stably mutational active Y527F (SrcA) pancreatic carcinoma cells. EGF causes cell metastasis and $\alpha v \beta 5$-mediated Rap1 activation. Rac1 and Rap1 activity are increased in FG cells plated on anti- $\beta 5$, but not anti- $\beta 1$, integrin antibodies after EGF therapy. Rap1 knockdown on vitronectin but not fibronectin prevents EGF-induced cell migration. In the chick CAM model, knocking down integrin $\beta 5$ expression prevents EGF-induced pulmonary metastasis but not primary tumor weight (92).

Nidogen (NID1 and NID2) are present in the BM and help maintain its stability by connecting COLIV and Ln networks in the $\operatorname{ECM}(93,94)$. The determination of NID2 methylation represents a biomarker for NSCLC diagnosis (95). The lung metastasis of NID1- or 2-deficient mice were studied after being intravenously injected with B16 murine melanoma cells. The authors demonstrated that the depletion of NID2, but not NID1, facilitates melanoma cell lung metastasis. According to histological and ultrastructural examination, the morphology and ultrastructure of BMs, including vessel BMs, are not different in NID1- and 2-deficient lungs. Furthermore, there is no difference in the deposition and distribution of the main BM components between the two mouse strains. These findings indicate that the absence of NID2 can cause subtle changes in endothelial BMs in the lung, allowing tumor cells to move through these BMs more quickly, resulting in a higher risk of metastasis and larger tumors (96). Further, NID2 inhibits liver metastasis in a significant way. NID2 suppresses the EGFR/Akt and integrin/focal adhesion kinase (FAK)/PLC metastasisrelated pathways; these data shed light on NID2's critical tumor metastasis-suppression functions in cancer (97). The roles of NID1 and NID2 in NSCLC have not yet been fully characterized.

\subsection{Proteoglycans}

Proteoglycans, key molecular effectors of cell surface and pericellular microenvironments, perform multiple roles in health and diseases because of their polyhedric structure and ability to interact with ligands and receptors that control neoplastic growth and neovascularization $(98,99)$. Some proteoglycans, like perlecan, have pro- and anti-angiogenic properties, while others, like syndecans and glypicans, can directly influence cancer growth by modulating key signaling pathways. Several groups of enzymes in the tumor microenvironment further regulate the bioactivity of these proteoglycans: (i) various proteinases, which cleave the protein core of pericellular proteoglycans, (ii) endosulfatases and heparanases which change the structure and bioactivity of various heparan sulfate proteoglycans and their bound growth factors, and (iii) sheddases, which cleave transmembrane or cell-associated syndecans and glypicans. On the other hand, small leucine-rich proteoglycans like lumican and decorin serve as tumor suppressors by physically antagonizing RTK such as EGFR and c-Met (receptor for HGF), evoking antisurvival and proapoptotic pathways (98).

Proteoglycans, including serglycin (100), perlecan (101), versican (102), aggrecans (103), decorin (104), lumican (105), syndecans (106), testicans (107), endocan (108), and glypicans (109) are involved in EGFR signaling pathways in lung cancer (108). For example, endocan is known to be a RTK ligand enhancer in tumorigenesis. Higher endocan levels are observed in lung tumors relative to non-neoplastic tissues, and these levels are associated with a poor prognosis in NSCLC patients with mutant EGFR. Circulating endocan levels are also significantly higher in patients with mutant EGFR than those with wild-type EGFR. Endocan enhances tumor growth driven by mutated EGFR by facilitating EGFR signaling through direct binding and enhancing the EGF-EGFR interaction. Through the Janus kinase (JAK)/STAT3 and ERK/ELK cascades, activated EGFR upregulates endocan expression, creating a positive regulatory 
loop of endocan-EGFR signaling. These results point to a novel relationship between EGFR and endocan and new strategies to target the endocan-EGFR regulatory axis in NSCLC patients with TKI-resistant (108). Another example is decorin, small leucinerich proteoglycans (SLRP) that control cell growth and migration in several tumor cell lines (104). Up-regulation of decorin inhibits proliferation, arrests the cell cycle at G1, and reduces invasive activity in the NSCLC A549 cells. Further, upregulating decorin substantially reduces EGFR phosphorylation, cyclin D1, TGF-1 expression and increases $p 53$ and P21 expression; whereas, decorin downregulation could reverse the effects (104). In the following section, we discuss the available data for syndecans and glypicans as examples for proteoglycans.

\subsubsection{Glypicans}

Glypicans (GPCs), a heparan sulfate proteoglycan (HSPG) family, consist of core proteins (60- to $70-\mathrm{kDa})$, heparan sulfate (HS) chains, and a glycosylphosphatidylinositol linkage (110). There are six known GPCs (GPC1-GPC6) in humans. GPCs participate in cell growth by regulating Wnt (111), development by modifying morphogen gradient formation (112), and other multiple signaling pathways. GPCs are abnormally expressed in multiple types of cancer and are crucial for cancer cell growth and progression. The expression of GPC5 is regulated to control cell growth and differentiation throughout mammalian development (113). Also, genetic variations of GPC5 may share in the increased risk of neversmokers (114). GPC5 mRNA and protein levels are overexpressed in A549 and H3255 cells. Using shRNAmediated knockdown or overexpression of GPC5, the migration rates of A549 and $\mathrm{H} 3255$ cells transfected with pRNAT-shRNA-GPC5 are lower than controls employing scratch and transwell assays. Using immunohistochemical staining, the high GPC5 expression level in NSCLC is linked to respiratory symptoms of lung cancer, regional lymph node metastasis, poor differentiation, vascular invasion, and a higher TNM stage. According to the Kaplan-Meier analysis, NSCLC patients with high levels of GPC5 expression have a shorter overall survival time relative to those with low levels of GPC5 expression (115). Conflicting data indicated that GPC5 is downregulated and linked to a poor prognosis in lung ADC tissues. Further, the loss of GPC5 expression is controlled by its hypermethylation, according to de-methylation experiments. GPC5 overexpression inhibits lung cancer cell proliferation, migration, and invasion in vitro and slows tumor growth in vivo, whereas GPC5 knockdown reverses these effects. Moreover, via binding Wnt3a on the cell surface, GPC5 inhibits Wnt/ $\beta$ catenin signaling, thereby mediating tumor suppressor action (113). Therefore, targeting particular GPCs in the tumor microenvironment that acts as ligands for inducing oncogenic pathways represents an effective cancer therapy strategy (100). Although the functions of GPCs have been assigned in different tumors, including lung (116), colon (117), and breast (118) cancers, esophageal squamous cell (119) carcinoma, and pancreatic ductal adenocarcinoma (120), their interaction with EGFR in NSCLC remains yet to be explored.

\subsubsection{Syndecans}

The syndecan (SDC) family is a transmembrane protein that possesses HS chains on their extracellular domains (121) and consists of four members (SDC1-SDC4). SDC-1 is frequently misexpressed in cancer and associated with invasion, metastasis, angiogenesis, and dedifferentiation (122-128). SDC-1 acts as a coreceptor for a wide range of growth factors (129), including bFGF and HB-EGF (130). A recent study reported that lung cancer has noticeable SDC-1, yet its expression does not associate with lung cancer patients' survival rate (121). However, a study by Shah et al. revealed that the expression of either NSCLC subtype classifiers EGFR and SDC-1 determined by tissue microarray is correlated with a $30 \%$ reduction in the risk of death. Loss of expression of these histologic classifiers is linked to aggressiveness in lung tumors and a poor prognosis (106). Besides, Zhu and colleagues interestingly reported that NSCLC patients with both a SDC4-ROS1 rearrangement and an activating EGFR mutation might acquire resistance to EGFRTKIs. Although the coexistence of two driver gene mutations in NSCLC is uncommon, triggering alterations of EGFR, ROS1, $A L K$, and KRAS have recently been recorded $(131,132)$.

\subsection{Non-proteoglycan Polysaccharides \\ 2.3.1 Hyaluronan (HA)}

$\mathrm{HA}$ is a plentiful constitute of the pericellular matrix that plays a vital role in regulating tissue homeostasis and cancer progression through its interaction with the cell surface receptor CD44 (133). HA synthesis is controlled by growth factors (e.g., EGF) and cytokines such as IL-1 $\beta$ (133). Three hyaluronan synthases (HAS) isoforms, including HAS1, HAS2, and HAS3, are known. CD44-HA interaction can modulate a variety of intracellular signaling by forming coreceptor complexes with many RTKs (e.g., EGFR) (134) that induce oncogenic pathways involved in cancer cell invasion, migration, and metastasis in the human MCF7 and TamR breast cancer cells (135). HA and CD44 are overexpressed in NHLFs/LCAFs (normal human lung fibroblasts vs. lung cancer-associated fibroblasts), followed by NSCLC cells. In NSCLC cells, exogenous HA somehow rescues the fault in cell proliferation and survival. Further, simultaneous silencing of HAS2 and HAS3 or CD44 suppresses the EGFR/ AKT/ERK signaling pathway, cell proliferation, and survival $(136,137)$. Of note, dual targeting CD44/EGFR by HA-based nanoparticles along with systemic administration of plasmid DNA expressing wild-type (wt-) p53 and microRNA-125b (miR-125b) in a genetically engineered mouse model of lung cancer led to an increase of wild-type $p 53$ and $m i R-125 b$ gene up to 20-fold associated with elevated caspase-3 and APAF-1 expression-induced apoptosis; thus it may represent an effective gene therapy for NSCLC (138).

Interestingly, treatment with EGF and IL-1 $\beta$, either alone or combined with TGF- $\beta$ in ADC, can stimulate HA production in A549 cell line, where treatment with TGF- $\beta / \mathrm{IL}-1 \beta$ changed cell morphology, induced EMT with altered vimentin and Ecadherin gene expression. Also, HAS3 overexpression induces HA synthesis, MMP9 expression, EMT phenotype, and MMP2 activities and increases invasion of epithelial ADC cell line H358 
(133). Induction of HA in H358 cells and adding exogenous HA in A549 cells significantly improved resistance to EGFR inhibitor Iressa. These results propose that increased HA production can promote EMT and Iressa resistance in NSCLC (133). Thus, regulating HA expression in NSCLC can be a new therapeutic strategy (133). Again, HA is implicated in EMT through EGF or TGF- $\beta 1$ signaling in lung cancer cell line A549, where TGF- $\beta 1$ upregulates HAS1, HAS2, and HAS3 expressions and augments CD44 expression interacts with EGFR, leading to the activation of the downstream signaling AKT and ERK pathways (139). On the contrary, pretreatment with HAS inhibitors such as 4methylumbelliferone (4-MU) can suppress TGF- $\beta 1$ 's impact on the expression of CD44 and EGFR and inhibit the CD44EGFR interaction. Collectively, these data indicate that HA/ CD44 interaction mediated by TGF- $\beta 1$ transactivates EGFR signaling, resulting in EMT induction in NSCLC cells (139).

\subsection{Fibrous ECM Proteins}

\subsubsection{Collagens}

Collagens (COLs) are the major ECM proteins (up to $30 \%$ of the total protein mass) in the human body. They are arranged in a relaxed meshwork and possess elasticity to extreme tensile strength owing to their surrounding proteins like elastin and glycoproteins (140). The individual structure of COLs can also create an intricate network that enables them to interact with each other and the surroundings (141). There are 28 known COL types and divided into specific subgroups according to their supramolecular assemblies, including a) fibrillar-forming COLs: the IM significant components such as COL type I, II, III, V, XI, XXVI, XXVII; b) the network-forming COLs: the main components of basement membrane such as type IV, VIII, X, and XVIII COLs (142). Of note, COLI, COLIII, and COLV are predominantly fibroblasts-derived COLs, while COLIV is mainly expressed by epithelial and endothelial cells (143); c) fibril-associated COLs with interrupted triple helices (FACITs) (e.g., IX, XII, XIV, XVI, XIX, XX, XXI, XXII, XXIV); and d) MACITs (membrane-anchored collagens with interrupted triple helices) such as type XIII, XVII, XXIII, and XXV COLs (144-146). COLIV is upregulated in NSCLC stroma, promoting the in vitro impairment of cell apoptosis and multidrug resistance. For example, NSCLC cells expressing COLIV are resistant to cis-platinum (DDP), which is mechanistically attributed to the PI3K pathway (147).

Notably, many studies addressed the significant effect of CAFs in tumorigenesis $(148,149)$. CAFs are the key players in COL dysregulation and turnover, resulting in desmoplasia (tumor fibrosis), where COLs deposit excessively in the tumor surroundings, crosslink, and linearize, thus increasing tissue stiffness (150). This influences the behavior of the nearby tumor cells and controls cell differentiation, proliferation, migration, gene expression, invasion, metastasis, and survival; thereby, directly affecting the cancer hallmarks (151). Tumor tissue with considerable fibroblast-derived COLs is correlated with poor outcomes (152-154). A study by $\mathrm{Li}$ et al. reported that the regulation of autocrine COLI expression for sustaining lung cancer cell growth in $3 \mathrm{D}$ cultures with fibroblasts provides a new insight for lung cancer targeted therapy (155). CAFs and other molecules can regulate COLs' expression in cancer cells, such as transcription factors, mutated genes, receptors, and signaling pathways; these molecules can also affect tumor cell behavior by integrins, RTKs (e.g., EGFR), and discoidin domain receptors (156).

In healthy tissues, the biosynthesis of COLs is highly controlled by a great counterbalance of many enzymes, including MMPs and their inhibitors and lysyl oxidases (LOX) $(157,158)$. In lung tumors, the stroma comprises a stiffer matrix than normal lung tissues due to more collagen modifications (159) mediated by lysyl hydroxylase-2 or procollagen-lysine, 2oxoglutarate 5-dioxygenase 2 (PLOD2) enzyme enhancing cell invasion and metastasis (160). Fibrotic collagen is primarily modified by PLOD2. PLOD2 was elevated in NSCLC specimens and was linked to a poor prognosis in NSCLC patients. PLOD2 directly enhances NSCLC metastasis by promoting migration and indirectly by inducing COL reorganization, evident by gain- and loss-of-function experiments and an orthotopic implantation metastasis model. In addition, PLOD2 regulation is achieved by PI3K/AKTFOXA1 axis. The transcription factor FOXA1 directly binds to the PLOD2 promoter for the transcription of PLOD2. These findings indicated that the NSCLC metastasis mechanism could be regulated by EGFR-PI3K/AKT-FOXA1-PLOD2 pathway and PLOD2 can be a therapeutic target for NSCLC treatment (161).

\section{INTEGRINS -ECM-INTERACTING CELL MEMBRANE RECEPTORS}

In tumorigenesis, a complex relationship is established between ECM proteins and key signaling pathway molecules (71). CellECM interactions are implicated in the intracellular signals that control gene expression, cell cycle progression, survival, movement, and physical support (162). Notably, these processes are governed by cell surface receptors that bind to ECM proteins called integrins. They are $\alpha, \beta$ heterodimeric transmembrane proteins implicated in many physiological and pathological processes such as adhesion to ECM, proliferation, survival, differentiation, and migration (163). Some integrins bind to the RGD motif on the ECM proteins, and the specificity of integrin binding to various ECM proteins is determined, partially through other amino acids neighboring the RGD sequence (164). Integrin cytoplasmic tails do not possess a kinase activity but activate specific intracellular non-receptor tyrosine kinases, such as FAK; thus, they recruit the Src kinase (165). Src phosphorylates several FAK-associated proteins, including tensin, paxillin, and the adaptor p130 Cas (CrkAssociated Substrate). To some extent, FAK activation results in the recruitment of other $\mathrm{SH} 2$-containing proteins, including PLC- $\gamma$, PI3K, and the adapter proteins Grb2 and Grb7, mediate ERK activation (165). The FAK/Src complex modulates small GTPase activity, leading to actin cytoskeleton remodeling required for cell adhesion and migration (166).

Upon integrins-ECM binding, numerous signaling molecules are activated, including cytoplasmic kinases, small GTPases, adapter proteins, and growth factor-RTKs (167). The ECM- 
and EGFR-activated signaling pathways have a high degree of functional interdependence. When EGFR interacts with ECM proteins, autophosphorylation increases in various cell types, including fibroblasts, smooth muscle, and kidney epithelial cells $(168,169)$., This type of overlapping signaling is thought to help or improve a variety of ECM and RTK-controlled cell functions, such as proliferation and survival (170). ECM interaction has been discovered to be essential for many EGF-mediated biological responses besides modulating EGFR signaling. EGF, for example, controls integrin-mediated cell migration, an actinbased mechanism that relies entirely on ECM component copresentation (171).

Numerous studies have suggested that integrin-RTK cooperation exists and plays an important role in cancer progression by controlling proliferation, invasion, and survival (172). Various mechanisms could control the crosstalk between integrins and RTKs, regardless of $\alpha$ or $\beta$ subunit catalytic activity. The integrins' ability to induce EGFR activation led to the regulation of Erk and Akt activation, which permitted adhesion-dependent induction of $\mathrm{p} 21$, cyclin $\mathrm{D} 1$ and $\mathrm{Rb}$ phosphorylation, and cdk4 activation in epithelial cells in the absence of exogenous growth factors. Epithelial cell adhesion to the ECM fails to efficiently induce p27 degradation, cdk2 activity, or cyclin A and Myc synthesis, and as a result, cells do not progress into the $S$ phase. Treatment of ECM-adherent cells with EGF (to induce EMT), or overexpression of EGFR or Myc, resulted in restoring late-G1 cell cycle events and progression into the $S$ phase. These findings suggest that integrin receptormediated partial activation of EGFR is significant in mediating events triggered by epithelial cell attachment to ECM (173). There are three major categories of integrin/RTK interactions (174) (Figure 4): (1) Integrins can physically bind to RTKs; (2) integrins clustering upon ECM binding can enhance signaling pathways triggered after ligand-dependent RTK activation, and (3) integrins and RTKs regulate their surface expression in a reciprocal manner (174). EGFR can interact with many integrins in different cancers, such as $\alpha 6 \beta 4$ (175), $\beta 1$ (170), and $\alpha v \beta 3$ (176), probably by forming a multimeric complex that also includes Src and the adaptor protein $\mathrm{p} 130^{\mathrm{Cas}}$ (176). This type of interaction is ligand-independent activation of the EGFR, leading to signaling involved in cell survival and proliferation in response to ECM (170) (Figure 4).

Emerging data indicate integrins' importance as essential EGFR signaling regulators in NSCLC (72, 177-179). For example, $\beta 1$ integrin silencing in human NSCLC A549 cells showed a defective activation of the EGFR signaling cascade, resulting in enhanced sensitivity to Gefitinib and cisplatin, reduced migration, and invasive behavior, and decreased in vitro proliferation and in vivo tumor growth. This silencing also increases the amount of cell surface EGFR, implying that $\beta 1$ integrin is required for efficient constitutive EGFR turnover at the cell membrane. Despite having no effect on the EGF internalization rate and recycling in silenced cells, EGFR signaling is recovered only by the Rab-coupling protein (RCP) expression, suggesting that $\beta 1$ integrin maintains the endocytic machinery required for EGFR signaling (177). Also, Integrin $\beta 4$ (ITGB4) expression is overexpressed in SCC compared with adenocarcinoma and associated with the presence of venous invasion, low overall patient survival. Using cBioPortal, a network map demonstrates the 50 most highly altered genes neighboring ITGB4 in SCC, which included genes in the EGFR and PI3K pathways and other known signaling partners as well as laminins, collagens, and CD151 (72). Moreover, CD151 drives cancer progression depending on integrin $\alpha 3 \beta 1$ through EGFR signaling in NSCLC. In detail, a high CD151 mRNA expression level is detected in NSCLC tissues and cell lines, and its high

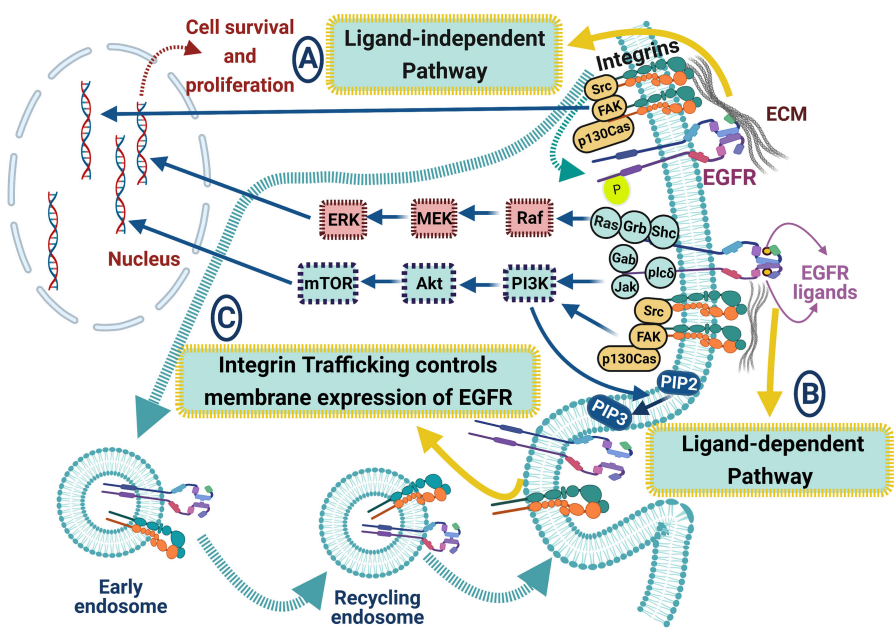

FIGURE 4 | ECM proteins and integrins regulate EGFR signaling pathways in lung cancer. The crosstalk between EGFR and integrins includes many signaling pathways: (A) ligand-independent pathway, where integrins can biochemically bind to EGFR leading to its activation. EGFR can interact with integrins via forming a multimeric complex (Src, FAK, and the adaptor protein p130Cas), leading to cell survival and proliferation, (B) ligand-dependent pathway, where integrin clustering enhances EGFR signaling cascades upon EGFR ligand binding, resulting in enhancing Akt, ERK, and Ras signaling pathways, and (C) integrin trafficking controls the membrane expression of EGFR. Blue arrows for stimulation; dashed red arrows for cellular effect, and red "T" sign for inhibition. 
expression was substantially related to the poor prognosis of NSCLC patients. Also, CD151 knockdown in vitro suppressed tumor proliferation, migration, and invasion. Further, overexpression of CD151 enhanced NSCLC growth in a mice model. NSCLC cells overexpressing CD151 exhibit migratory and invasive phenotype via interacting with integrins and regulating the downstream signaling pathways of EGFR/ErbB2 (179). Interestingly, the inhibition of EGFR in NSCLC cell lines reduces tyrosine phosphorylation of neural precursor cell expressed, developmentally down-regulated 9 (NEDD9), an integrin signaling adaptor protein that consists of multiple domains serving as substrate for various tyrosine kinases. Overexpression of constitutively active EGFR, in the absence of integrin stimulation, leads to tyrosine phosphorylation of NEDD9, which plays a pivotal role in the in vitro cell migration and invasion of NSCLC cells. Moreover, NEDD9 overexpression promoted lung metastasis of an NSCLC cell line in NOD/Shi-scid, IL-2R $\gamma$ (null) mice (NOG) mice (178). Overall, these data show that integrins-dependent EGFR interactions might represent a prognostic marker and potential therapeutic targets in NSCLC.

\section{KEY ECM REMODELING ENZYMES}

Matrix degradation is a finely regulated process that occurs simultaneously with the formation of new ECM molecules. Tissue integrity is achieved through the actions of matrixdegrading enzymes such as matrix metalloproteinases (MMPs) and their endogenous inhibitors (TIMPs), adamalysin group (ADAMs and ADAMTS), cathepsins, plasminogen activation system components, and glycolytic enzymes such as heparanase (HPSE) and hyaluronidases (HYALs) that cleave heparan sulfate (HS)/heparin chains on hyaluronan (HA) and proteoglycans (PGs) (180, 181). Elastase, dipeptidyl peptidase IV (DPPIV), and tissue kallikrein are ECM serine proteases that play distinct functions in matrix proteolysis and have been linked to cancer progression (182-184). MMPs are the major catabolic matrix endopeptidases linked to a number of normal processes such as wound healing, immunological response, differentiation, tissue homeostasis, and diseases such as osteoarthritis neuroinflammation, atherosclerosis, and cancer (185). The human genome contains 24 MMP members, which are classified into secreted and membrane-bound MMPs. MMPs are categorized as matrilysins, gelatinases, furin-activated collagenases, stromelysins, and other MMPs based on substrate specificity $(186,187)$. MMPs are mediators of the tumor microenvironment alternations during cancer growth because they enhance EMT, cancer cell signaling, migration, invasion, autophagy, and angiogenesis, which aid tumor progression and metastasis (188). We focus on the functional interplay between MMPs and EGFR in NSCLC in the next sections.

\subsection{Metalloproteinases (MMPs)}

MMPs are a group of 24 proteinases, also known as matrix MMPs, matrixins, and zinc-dependent endopeptidases (189). Transcription of most matrixins is regulated by growth factors, hormones, cytokines, and cellular transformation. MMPs' proteolytic activities are tightly controlled during their activation from their precursors and inhibition by the endogenous inhibitors TIMPs and a-macroglobulins (190). Aberrant expression of MMPs is associated with many diseases, including lung cancer (191). MMPs perform their proteolytic activity autonomously in the alveolar space for any changes in the cleaved protein properties (192). Cancer cells secrete many MMPs that remodel and degrade the BM in lung cancer tissue, creating a dynamic flow of pro- and antitumor signals $(190,191)$. The regulation of MMPs expression occurs by triggering inflammatory molecules and hormones and intercellular and matrix interactions (190). MMPs are present in low levels in normal adult tissues, yet the MMPs expression is upregulated during wound healing, tissue repair, or remodeling under pathogenic conditions (192).

When the ECM collagen becomes abundant, large amounts of MMPs are secreted in tumor tissues, and BM remodeling occurs (193, 194), leading to complex chaos of pro-and antitumor signals originating from BM degradation products and enhancing the invasive phenotype of malignant cells (195). In both mouse and human NSCLC, MMP14 is significantly upregulated in intratumoral myeloid compartments and tumor epithelial cells. In an orthotopic (K-Ras ${ }^{\mathrm{G} 12 \mathrm{D} /+} \mathrm{p} 53^{-/-}$) mouse model of lung cancer, overexpression of a soluble dominantnegative MMP14 (DN-MMP14) or pharmacological inhibition of MMP14 blocks the invasion of lung cancer cells in collagen I matrix in vitro and reduces tumor incidence. MMP14 activity also triggers the proteolytic processing and activation of Heparin-Binding EGF-like growth factor (HB-EGF), which stimulates the EGFR signaling pathway and increases tumor proliferation and growth. These data pinpoint the potential for developing therapeutic strategies that target MMP14 in NSCLC, specifically targeting the MMP14-HB-EGF axis (191). Increased expression of MMP-9 in vitro and in vivo has been linked to tumor progression. Cox et al. linked the EGFR expression with MMP-9 upregulation in tumor cells in vitro in NSCLC patients. MMP-9 expression strongly correlated with EGFR expression and EGFR membranous expression, but not with cytoplasmic EGFR expression. MMP-9 and EGFR co-expression is associated with a poorer prognosis in NSCLC patients. Also, MMP-9 and EGFR are expressed in a large proportion of NSCLC tumors. The presence of these markers together indicates a poor prognosis. These findings suggest that the EGFR signaling pathway, via specific up-regulation of MMP-9, can play a key role in NSCLC invasion (196).

\section{EFFECT OF ECM COMPONENTS' EXPRESSION AND INTERACTIONS ON SENSITIVITY TO TKI THERAPY}

The biological features of the tumor microenvironment are affected by cancer cells, non-cancerous cells, and ECM (197). The interactions between different cell types within the tumor microenvironment play a key role in developing resistance to the 
anticancer drugs (198). The most abundant matrix protein in the cancer stroma, COLI, promotes tumor progression by facilitating cancer cell growth, invasion, and metastasis $(199,200)$. Also, COLI supports anticancer drug resistance through the integrin signaling pathway (201). Besides, COLI induces EGFR-TKI resistance in EGFR-mutated cancer cells (202). Moreover, the results of Wang et al. reported that COLI drives EGFR-TKI resistance through integrin- $\beta$ (23). Knockdown of integrin- $\beta 1$ significantly suppresses the resistance driven by both COLI and de-cellularized ECM, indicating that COLI and integrin- $\beta 1$ could mediate the resistance-driving function of ECM and might be useful interventional therapeutic strategies. Further, a collagen synthesis inhibitor, CHP (cis-4-Hydroxy-L-proline), efficiently inhibiting collagen production and synergizing with osimertinib, leads to growth suppression of GFP-labeled H1975 cells co-cultured with parental H1975 cells or fibroblasts (23). Interleukin-6 (IL-6) plays a vital role in developing interstitial fibroblastic proliferation induced by EGFR-TKI. In lung cancer, A549 cell lines treated with EGFRTKIA reduce cell viability via increment of IL- 6 mRNA and protein expression. IL- 6 treatment increases $\alpha$-actin and collagen expression, fibrosis markers, in lung fibroblast cells using a coculture model. These findings indicate that IL-6 plays a role in EGFR-TKI-induced interstitial fibroblastic proliferation. Therefore, inhibiting IL-6 could be helpful to cancer patients receiving EGFR-TKI treatment to reduce the risk of side effects (203). Further, in EGFR mutated lung ADC patients, FG2A level was related to EGFR-TKI response, and FGA2 represented a predictor of targeted therapy for EGFR-mutated lung (79). Furthermore, integrin $\beta 1$ promotes Src-Akt pathway activation and induces erlotinib resistance (201). COLI is dysregulated in the bone, and other solid tumors influence tumor cell behavior inducing EMT, including the lung (204) and breast (205). The sensitivity of EGFR-TKI in EGFR-mutated cancer cells cultured with COLI was investigated when COLI activated mTOR via Akt and ERK1/2-independent pathway in NSCLC, leading to EGFRTKI resistance. Combining EGFR-TKI and mTOR inhibitors may be a viable option for combating such resistance (206). ECM components are internalized and used as nutrients by cells through several mechanisms. For example, the degradation of ECM proteins into peptides by MMPs and internalization of the degraded peptide fragments by cells. Another mechanism involves endocytosis of ECM macromolecules $(207,208)$. Rac1 inhibition reduces COLI uptake in mutated lung cancer cells (PC-9) and restores their sensitivity to EGFR-TKI. Racl is needed for micropinocytosis and reduction of COLI uptake. Thus, EGFRTKI resistance can evolve in EGFR-mutated lung cancer cells via COLI uptake mediated by micropinocytosis (202).

EMT is characterized by the downregulation of epithelial markers, especially E-cadherin, and upregulation of mesenchymal markers such as vimentin, N-cadherin, and fibronectin (209). EMT is essential in the primary resistance of erlotinib in the EGFR-TKI responsive EGFR-mutant lung cancer cell line $(210,211)$. The expression of EGFR and EMT-related proteins are noticeably modulated in the peripheral leading edge of NSCLCs associated with poor prognosis (212). In NSCLC, EMT is a key player in controlling sensitivity or resistance to
EGFR inhibition. NSCLC lines expressing E-cadherin showed higher sensitivity to EGFR inhibition in vitro and xenografted models, whereas NSCLC lines expressing vimentin and/or fibronectin showed resistance to the growth inhibitory effects of EGFR kinase inhibition (210).

FBLN1 isoforms regulate EGFR signaling and function in NSCLC. FBLN1 loss, using siRNA mediated knockdown of FBLN1C and FBLN1D, in NSCLC Calu-1 cells significantly increased EGF mediated EGFR activation, inhibited EGFR activation, promoted EGFR-dependent cell migration that inhibited upon Erlotinib treatment. Notably, FBLN1C and FBLN1D knockdown cells show a substantial increase in EGFmediated EGFR activation, which promotes cell adhesion reduced by Erlotinib treatment. These data point out that FBLN1C/1D, as an ECM protein, can bind and regulate EGFR function and activation in NSCLC Calu-1 cells, highlighting tumor ECM role in affecting EGFR dependent lung cancers (6). In H1975/EGFR (L858R/ T790M) cells, stable silencing of MUC1-C downregulates AKT signaling and inhibits colony formation, growth, and tumorigenicity. Similar results were found during MUC1-C silencing in gefitinib-resistant PC9GR cells that express EGFR (delE746_A750/T790M). Further, inhibition of MUC1-C suppresses the activation of EGFR (T790M), AKT, ERK, and MEK activation, colony formation, and tumorigenicity. Treatment of PC9GR and H1975 cells with GO-203 inhibits MUC1-C homodimerization, results in EGFR, AKT, and MEK/ ERK signaling inhibition, as well as loss of survival. The combination of GO-203 and the irreversible EGFR inhibitor afatinib acts in synergism to inhibit the growth of NSCLC cells harboring activating EGFR (T790M) or EGFR (delE746-A750) mutants (213).

The activation of many signaling pathways imperils the clinical efficacy of EGFR-TKIs in EGFR-mutated NSCLC (214-218). The interactions between tumor cells and the extracellular environment are regulated by an integrin-linked kinase (ILK) to promote cell proliferation, migration, and EMT. Src homology 2 domaincontaining phosphatase 2 (SHP2) is essential for MAPK pathway and RTK signaling activation. In baseline tumor specimens, highly expressed ILK mRNA is associated with poor prognostic factors for patient-free survival in the univariate and multivariate Cox regression models (214). Integrin $\beta 3$ was significantly and consistently overexpressed in acquired osimertinib- or gefitinibresistant lung cancer in vitro and in vivo and involved in the progression of lung ADC. Antagonizing integrin $\beta 3$ improved the TKI sensitivity in vitro and in vivo, inhibiting anoikis resistance, proliferation, and EMT phenotype in lung cancer cells. Integrin $\beta 3$ overexpression was also linked to the enhanced cancer stemness implicated in resistance development. Mechanistically, integrin $\beta 3$ is induced by increased levels of TGF $\beta 1$ in acquired TKI-resistant lung cancer, which indicates the TGF $\beta 1$ /integrin $\beta 3$ axis as a potential target for combination therapy in EGFR-mutant lung cancer to overcome acquired resistance to EGFR TKIs (215). Furthermore, azurin, an anticancer therapeutic protein, controls integrin $\beta 1$ levels, and its appropriate membrane localization suppressed the intracellular downstream signaling cascades of integrins and the invasiveness of NSCLC A549 cells. Further, 
azurin combined with erlotinib and gefitinib enhances the sensitivity of NSCLC A549 cells to azurin. The stiffness of A549 lung cancer cells decreased with exposure to azurin and gefitinib using Young's module (E), suggesting that the changes in the membrane properties are the principal of the broad anticancer activity of azurin, and it may be relevant as an adjuvant to enhance the effects of other clinical anticancer agents (216). The expression levels of EGFR and integrin $\alpha 2$ and $\beta 1$ subunits were significantly elevated in Ionizing radiation (IR) cells. Importantly, functional blockade of integrin $\alpha 2 \beta 1$ or treatment with EGFR-TKI, PD168393, resulted in a round morphology of cells and revoked their invasion in the collagen matrix. Further, higher activation of Erk1/2 and Akt signaling molecules in IR cells. Inhibition of Akt activation by treating with PI3K inhibitor LY294002 decreased IR cell invasion, yet MEK inhibitor U0126 did not inhibit Erk1/2 activation, which indicates integrin $\alpha 2 \beta 1$ and EGFR mutually promote higher invasiveness mediated by the PI3K/Akt signaling pathway in IRsurvived lung cancer cells and might provide alternative targets along with radiotherapy (217). Recently, EGFR inhibitors' resistance was delayed by co-delivering EGFR and integrin $\alpha v \beta 3$ inhibitors with nanoparticles in NSCLC. The enhanced expression of integrin $\alpha v \beta 3$ is observed in tumor tissues of patients resistant to EGFR inhibitors. Further, integrin $\alpha v \beta 3$-positive NSCLC cells unveiled significant EGFR inhibitor resistance, leading to activating Galectin-3/KRAS/RalB/TBK1/NF- $\kappa \mathrm{B}$ signaling pathway. Interestingly, co-encapsulating erlotinib and cilengitide by MPEG-PLA (Erlo+Cilen/PP) nanoparticles enhanced the drug delivery system, leading to reduced systemic toxicity and superior anti-cancer effects (218).

\section{CONCLUSION AND FUTURE PERSPECTIVES}

ECM components, along with integrin and MMPs, regulate many cellular processes relevant to lung cancer progression,

\section{REFERENCES}

1. Ferlay J, Colombet M, Soerjomataram I, Mathers C, Parkin DM, Piñeros M, et al. Estimating the Global Cancer Incidence and Mortality in 2018: GLOBOCAN Sources and Methods. Int J Cancer (2019) 144:1941-53. doi: 10.1002/ijc.31937

2. Travis WD, Brambilla E, Nicholson AG, Yatabe Y, Austin JHM, Beasley MB, et al. The 2015 World Health Organization Classification of Lung Tumors: Impact of Genetic, Clinical and Radiologic Advances Since the 2004 Classification. J Thorac Oncol (2015) 10:1243-60. doi: 10.1097/ JTO.0000000000000630

3. Molina JR, Yang P, Cassivi SD, Schild SE, Adjei AA. Non-Small Cell Lung Cancer: Epidemiology, Risk Factors, Treatment, and Survivorship. Mayo Clin Proc (2008) 83(5):584-94. doi: 10.4065/83.5.584

4. Fidler IJ. Critical Determinants of Metastasis. Semin Cancer Biol (2002) 12:89-96. doi: 10.1006/scbi.2001.0416

5. Minna JD, Roth JA, Gazdar AF. Focus on Lung Cancer. Cancer Cell (2002) 1:49-52. doi: 10.1016/S1535-6108(02)00027-2

6. Spivey KA, Banyard J, Solis LM, Wistuba II, Barletta JA, Gandhi L, et al. Collagen XXIII: A Potential Biomarker for the Detection of Primary and Recurrent Non-Small Cell Lung Cancer. Cancer Epidemiol Biomarkers Prev (2010) 19:1362-72. doi: 10.1158/1055-9965.EPI-09-1095 including cell proliferation, adhesion, and migration through their direct or indirect interactions with EGFR. ECM proteins associated with poor NSCLC prognosis via crosstalk with EGFR, including COLs, MMP-9, MUC1, MUC5AC, Ln 5, and GPC5. Many ECM proteins can be used as therapeutic targets, such as COLs, PLOD2, FBLN3, MUC5AC, FN, FAG2, FG, GPC3, and HA by modulating their interaction with EGFR. ECM proteins can be tumor-suppressing or -promoting depending on their signaling context with EGFR and many signaling molecules. Despite the emerging data revealing the role of ECM components or/and EGFR in NSCLC, many gaps still exist in EGFR-ECM interactions. The correlation between EGFR and many ECM proteins, including COLI, COLIV, FBLN1, FBLN3, FBLN5 MUC1, MUC5, MUC6, and Ln5 was revealed, yet EGFR interactions with other types of COLs, MUC and Ln, FG, TN, Postn, VTN, NID, TSP, and versican in NSCLC still need further investigations. A future better understanding of the interactions between ECM components and EGFR-TKI might provide new insights for developing new therapeutic strategies for NSCLC patients.

\section{AUTHOR CONTRIBUTIONS}

Conceptualization, $\mathrm{SH}$ and SI. Literature searches, SH and SI. Data curation, SI, SH, and AA. Investigation, SH, SI, and AA. Supervision, AA and SI. Figures design, SH. Writing-original draft, SH and SI. Writing-review and editing, SH, SI, and AA. This article is based primarily on the student MSc. thesis, SH. All authors have read and agreed to the published version of the manuscript.

\section{ACKNOWLEDGMENTS}

All the figures were created with BioRender.com.

7. Vallath S, Hynds RE, Succony L, Janes SM, Giangreco A. Targeting EGFR Signalling in Chronic Lung Disease: Therapeutic Challenges and Opportunities. Eur Respir J (2014) 44:513-22. doi: 10.1183/09031936.00146413

8. Zhang H, Berezov A, Wang Q, Zhang G, Drebin J, Murali R, et al. ErbB Receptors: From Oncogenes to Targeted Cancer Therapies. J Clin Invest (2007) 117:2051-8. doi: 10.1172/JCI32278

9. Graus-Porta D, Beerli RR, Daly JM, Hynes NE. ErbB-2, the Preferred Heterodimerization Partner of All ErbB Receptors, is a Mediator of Lateral Signaling. EMBO J (1997) 16:1647-55. doi: 10.1093/emboj/16.7.1647

10. Lemmon MA. Ligand-Induced ErbB Receptor Dimerization. Exp Cell Res (2009) 315:638-48. doi: 10.1016/j.yexcr.2008.10.024

11. Yarden Y, Sliwkowski MX. Untangling the ErbB Signalling Network. Nat Rev Mol Cell Biol (2001) 2:127-37. doi: 10.1038/35052073

12. Jorissen RN, Walker F, Pouliot N, Garrett TPJ, Ward CW, Burgess AW. Epidermal Growth Factor Receptor: Mechanisms of Activation and Signalling. Exp Cell Res (2003) 284:31-53. doi: 10.1016/S0014-4827(02)00098-8

13. Bethune G, Bethune D, Ridgway N, Xu Z. Epidermal Growth Factor Receptor (EGFR) in Lung Cancer: An Overview and Update. J Thorac Dis (2010) 2(1):48-51.

14. Burgel PR, Nadel JA. Epidermal Growth Factor Receptor-Mediated Innate Immune Responses and Their Roles in Airway Diseases. Eur Respir J (2008) 32(1):1068-81. doi: 10.1183/09031936.00172007 
15. Lynch TJ, Bell DW, Sordella R, Gurubhagavatula S, Okimoto RA, Brannigan BW, et al. Activating Mutations in the Epidermal Growth Factor Receptor Underlying Responsiveness of Non-Small-Cell Lung Cancer to Gefitinib. N Engl J Med (2004) 350:2129-39. doi: 10.1056/nejmoa040938

16. Yue B. Biology of the Extracellular Matrix: An Overview. J Glaucoma (2014) 23:S20-3. doi: 10.1097/IJG.0000000000000108

17. Järveläinen H, Sainio A, Koulu M, Wight TN, Penttinen R. Extracellular Matrix Molecules: Potential Targets in Pharmacotherapy. Pharmacol Rev (2009) 61:198-223. doi: 10.1124/pr.109.001289

18. Theocharis AD, Skandalis SS, Gialeli C, Karamanos NK. Extracellular Matrix Structure. Adv Drug Deliv Rev (2016) 97:4-27. doi: 10.1016/ j.addr.2015.11.001

19. Lv H, Liu R, Fu J, Yang Q, Shi J, Chen P, et al. Epithelial Cell-Derived Periostin Functions as a Tumor Suppressor in Gastric Cancer Through Stabilizing P53 and E-Cadherin Proteins via the Rb/E2F1/p14ARF/Mdm2 Signaling Pathway. Cell Cycle (2014) 13:2962-74. doi: 10.4161/ 15384101.2014.947203

20. Wong GS, Rustgi AK. Matricellular Proteins: Priming the Tumour Microenvironment for Cancer Development and Metastasis. $\mathrm{Br} J$ Cancer (2013) 108:755-61. doi: 10.1038/bjc.2012.592

21. Mueller MM, Fusenig NE. Friends or Foes - Bipolar Effects of the Tumour Stroma in Cancer. Nat Rev Cancer (2004) 4:839-49. doi: 10.1038/nrc1477

22. Hassanein SS, Ibrahim SA, Abdel-Mawgood AL. Cell Behavior of Non-Small Cell Lung Cancer Is at EGFR and MicroRNAs Hands. Int J Mol Sci (2021) 22 (22):12496. doi: 10.3390/IJMS222212496

23. Wang Y, Zhang T, Guo L, Ren T, Yang Y. Stromal Extracellular Matrix is a Microenvironmental Cue Promoting Resistance to EGFR Tyrosine Kinase Inhibitors in Lung Cancer Cells. Int J Biochem Cell Biol (2019) 106:96-106. doi: 10.1016/j.biocel.2018.11.001

24. De Vega S, Iwamoto T, Yamada Y. Fibulins: Multiple Roles in Matrix Structures and Tissue Functions. Cell Mol Life Sci (2009) 66:1890-902. doi: 10.1007/s00018-009-8632-6

25. Gallagher WM, Currid CA, Whelan LC. Fibulins and Cancer: Friend or Foe? Trends Mol Med (2005) 11:336-40. doi: 10.1016/j.molmed.2005.06.001

26. Twal WO, Czirok A, Hegedus B, Knaak C, Chintalapudi MR, Okagawa H, et al. Fibulin-1 Suppression of Fibronectin-Regulated Cell Adhesion and Motility - PubMed. J Cell Sci (2001) 114:4587-98. doi: 10.1242/jcs. 114.24 .4587

27. Obaya AJ, Rua S, Moncada-Pazos A, Cal S. The Dual Role of Fibulins in Tumorigenesis. Cancer Lett (2012) 325:132-8. doi: 10.1016/j.canlet.2012.06.019

28. Harikrishnan K, Joshi O, Madangirikar S, Balasubramanian N. Cell Derived Matrix Fibulin-1 Associates With Epidermal Growth Factor Receptor to Inhibit Its Activation, Localization and Function in Lung Cancer Calu-1 Cells. Front Cell Dev Biol (2020) 8:522. doi: 10.3389/fcell.2020.00522

29. Kim IG, Kim SY, Choi SI, Lee JH, Kim KC, Cho EW. Fibulin-3-Mediated Inhibition of Epithelial-to-Mesenchymal Transition and Self-Renewal of ALDH+ Lung Cancer Stem Cells Through IGF1R Signaling. Oncogene (2014) 33:3908-17. doi: 10.1038/onc.2013.373

30. Yue W, Dacic S, Sun Q, Landreneau R, Guo M, Zhou W, et al. Frequent Inactivation of RAMP2, EFEMP1 and Dutt1 in Lung Cancer by Promoter Hypermethylation. Clin Cancer Res (2007) 13:4336-44. doi: 10.1158/10780432.CCR-07-0015

31. Hwang CF, Chien CY, Huang SC, Yin YF, Huang CC, Fang FM, et al. Fibulin-3 is Associated With Tumour Progression and a Poor Prognosis in Nasopharyngeal Carcinomas and Inhibits Cell Migration and Invasion via Suppressed AKT Activity. J Pathol (2010) 222:367-79. doi: 10.1002/ path. 2776

32. Kim EJ, Lee SY, Woo MK, Choi SI, Kim TR, Kim MJ, et al. Fibulin-3 Promoter Methylation Alters the Invasive Behavior of Non-Small Cell Lung Cancer Cell Lines via MMP-7 and MMP-2 Regulation. Int J Oncol (2012) 40:402-8. doi: 10.3892/ijo.2011.1191

33. Chen X, Meng J, Yue W, Yu J, Yang J, Yao Z, et al. Fibulin-3 Suppresses Wnt/ $\beta$-Catenin Signaling and Lung Cancer Invasion. Carcinogenesis (2014) 35:1707-16. doi: 10.1093/carcin/bgu023

34. You L, He B, Xu Z, Uematsu K, Mazieres J, Mikami I, et al. Inhibition of Wnt-2-Mediated Signaling Induces Programmed Cell Death in Non-SmallCell Lung Cancer Cells. Oncogene (2004) 23:6170-4. doi: 10.1038/ sj.onc. 1207844
35. Nguyen DX, Chiang AC, Zhang XHF, Kim JY, Kris MG, Ladanyi M, et al. WNT/TCF Signaling Through LEF1 and HOXB9 Mediates Lung Adenocarcinoma Metastasis. Cell (2009) 138:51-62. doi: 10.1016/ j.cell.2009.04.030

36. Xu S, Yang Y, Sun YB, Wang HY, Sun CB, Zhang X. Role of Fibulin-3 in Lung Cancer: In Vivo and In Vitro Analyses. Oncol Rep (2014) 31:79-86. doi: 10.3892/or.2013.2799

37. Nakamura T, Ruiz-Lozano P, Lindner V, Yabe D, Taniwaki M, Furukawa Y, et al. DANCE, a Novel Secreted RGD Protein Expressed in Developing, Atherosclerotic, and Balloon-Injured Arteries. J Biol Chem (1999) 274:22476-83. doi: 10.1074/jbc.274.32.22476

38. Albig AR, Neil JR, Schiemann WP. Fibulins 3 and 5 Antagonize Tumor Angiogenesis in vivo. Cancer Res (2006) 66:2621-9. doi: 10.1158/00085472.CAN-04-4096

39. Nakamura T, Lozano PR, Ikeda Y, Iwanaga Y, Hinek A, Minamisawa S, et al. Fibulin-5/DANCE Is Essential for Elastogenesis In Vivo. Nature (2002) 415:171-5.

40. Timpl R, Sasaki T, Kostka G, Chu ML. Fibulins: A Versatile Family of Extracellular Matrix Proteins. Nat Rev Mol Cell Biol (2003) 4:479-89.

41. Yanagisawa H, Davis EC, Starcher BC, Ouchi T, Yanagisawa M, Richardson JA, et al. Fibulin-5 Is an Elastin-binding Protein Essential for Elastic Fiber Development In Vivo. Nature (2002) 415:168-71.

42. Kuang P-P, Goldstein RH, Liu Y, Rishikof DC, Jean J-C, Joyce-Brady M. Coordinate Expression of Fibulin-5/DANCE and Elastin During Lung Injury Repair. Am J Physiol Lung Cell Mol Physiol (2003) 285:1147-52. doi: 10.1152/ajplung.00098.2003.-Fibulin-5

43. Schiemann WP, Blobe GC, Kalume DE, Pandey A, Lodish HF. ContextSpecific Effects of Fibulin-5 (DANCE/EVEC) on Cell Proliferation, Motility, and Invasion. Fibulin-5 is Induced by Transforming Growth Factor- $\beta$ and Affects Protein Kinase Cascades. J Biol Chem (2002) 277:27367-77. doi: $10.1074 /$ jbc.M200148200

44. Yue W, Sun Q, Landreneau R, Wu C, Siegfried JM, Yu J, et al. Fibulin-5 Suppresses Lung Cancer Invasion by Inhibiting Matrix Metalloproteinase-7 Expression. Cancer Res (2009) 69:6339-46. doi: 10.1158/0008-5472.CAN09-0398

45. Lee HK, Kwon MJ, Seo J, Kim JW, Hong M, Park HR, et al. Expression of Mucins (MUC1, MUC2, MUC5AC and MUC6) in ALK-Positive Lung Cancer: Comparison With EGFR-Mutated Lung Cancer. Pathol Res Pract (2019) 215:459-65. doi: 10.1016/j.prp.2018.12.011

46. Kufe DW. Mucins in Cancer: Function, Prognosis and Therapy. Nat Rev Cancer (2009) 9:874-85. doi: 10.1038/nrc2761

47. Li Y, Ren J, Yu WH, Li Q, Kuwahara H, Yin L, et al. The Epidermal Growth Factor Receptor Regulates Interaction of the Human DF3/MUC1 Carcinoma Antigen With C-Src and $\beta$-Catenin. J Biol Chem (2001) 276:35239-42. doi: 10.1074/jbc.C100359200

48. Raina D, Kosugi M, Ahmad R, Panchamoorthy G, Rajabi H, Alam M, et al. Dependence on the MUC1-C Oncoprotein in Non-Small Cell Lung Cancer Cells. Mol Cancer Ther (2011) 10:806-16. doi: 10.1158/15357163.MCT-10-1050

49. Yao M, Zhang W, Zhang Q, Xing L, Xu A, Liu Q, et al. Overexpression of MUC1 Enhances Proangiogenic Activity of Non-Small-Cell Lung Cancer Cells Through Activation of Akt and Extracellular Signal-Regulated Kinase Pathways. Lung (2011) 189:453-60. doi: 10.1007/s00408-011-9327-y

50. Pochampalli MR, Bejjani RME, Schroeder JA. MUC1 Is a Novel Regulator of ErbB1 Receptor Trafficking. Oncogene (2007) 26:1693-701. doi: 10.1038/ sj.onc. 1209976

51. MacDermed DM, Khodarev NN, Pitroda SP, Edwards DC, Pelizzari CA, Huang L, et al. MUC1-Associated Proliferation Signature Predicts Outcomes in Lung Adenocarcinoma Patients. BMC Med Genomics (2010) 3:16. doi: $10.1186 / 1755-8794-3-16$

52. Ahmad R, Raina D, Joshi MD, Kawano T, Ren J, Kharbanda S, et al. MUC1C Oncoprotein Functions as a Direct Activator of the Nuclear Factor- $\mathrm{\kappa b}$ P65 Transcription Factor. Cancer Res (2009) 69:7013-21. doi: 10.1158/00085472.CAN-09-0523

53. Huang L, Chen D, Liu D, Yin L, Kharbanda S, Kufe D. MUC1 Oncoprotein Blocks Glycogen Synthase Kinase $3 \beta$-Mediated Phosphorylation and Degradation of $\beta$-Catenin. Cancer Res (2005) 65:10413-22. doi: 10.1158/ 0008-5472.CAN-05-2474 
54. Ahmad R, Rajabi H, Kosugi M, Joshi MD, Alam M, Vasir B, et al. MUC1-C Oncoprotein Promotes STAT3 Activation in an Autoinductive Regulatory Loop. Sci Signal (2011) 4(160):ra9. doi: 10.1126/scisignal.2001426

55. Ramasamy S, Duraisamy S, Barbashov S, Kawano T, Kharbanda S, Kufe D. The MUC1 and Galectin-3 Oncoproteins Function in a MicroRNA-Dependent Regulatory Loop. Mol Cell (2007) 27:992-1004. doi: 10.1016/j.molcel.2007.07.031

56. Wakata K, Tsuchiya T, Tomoshige K, Takagi K, Yamasaki N, Matsumoto K, et al. A Favourable Prognostic Marker for EGFR Mutant non-Small Cell Lung Cancer: Immunohistochemical Analysis of MUC5B. BMJ Open (2015) 5(7):e008366. doi: 10.1136/bmjopen-2015-008366

57. Michaël D, Martine A, Nathalie R, Anita R, Anne MLF, Roger L, et al. Lepidic Predominant Adenocarcinoma and Invasive Mucinous Adenocarcinoma of the Lung Exhibit Specific Mucin Expression in Relation With Oncogenic Drivers. Lung Cancer (2017) 109:92-100. doi: 10.1016/j.lungcan.2017.05.007

58. Matsumura M, Okudela K, Nakashima Y, Mitsui H, Denda-Nagai K, Suzuki T, et al. Specific Expression of MUC21 in Micropapillary Elements of Lung Adenocarcinomas - Implications for the Progression of EGFR-Mutated Lung Adenocarcinomas. PLoS One (2019) 14(4):e0215237. doi: 10.1371/ journal.pone.0215237

59. Dong Y, Dong Y, Zhou L, Zhao D, Li K, Liu Z, et al. MUC5AC Enhances Tumor Heterogeneity in Lung Adenocarcinoma With Mucin Production and is Associated With Poor Prognosis. Jpn J Clin Oncol (2020) 50:701-11. doi: 10.1093/jjco/hyaa016

60. Lakshmanan I, Ponnusamy MP, Macha MA, Haridas D, Majhi PD, Kaur S, et al. Mucins in Lung Cancer: Diagnostic, Prognostic, and Therapeutic Implications. J Thorac Oncol (2015) 10:19-27. doi: 10.1097/JTO.0000000000000404

61. Singh P, Carraher C, Schwarzbauer JE. Assembly of Fibronectin Extracellular Matrix. Annu Rev Cell Dev Biol (2010) 26:397-419. doi: 10.1146/annurev-cellbio-100109-104020

62. Zollinger AJ, Smith ML. Fibronectin, the Extracellular Glue. Matrix Biol (2017) 60-61:27-37. doi: 10.1016/j.matbio.2016.07.011

63. Pankov R, Yamada KM. Fibronectin at a Glance. J Cell Sci (2002) 115:38613. doi: $10.1242 /$ jcs.00059

64. Cho C, Horzempa C, Longo CM, Peters DM, Jones DM, McKeown-Longo PJ. Fibronectin in the Tumor Microenvironment Activates a TLR4Dependent Inflammatory Response in Lung Cancer Cells. J Cancer (2020) 11:3099-105. doi: 10.7150/jca.39771

65. Wang JP, Hielscher A. Fibronectin: How its Aberrant Expression in Tumors may Improve Therapeutic Targeting. J Cancer (2017) 8:674-82. doi: 10.7150/ jca.16901

66. You R, Zheng M, McKeown-Longo PJ. The First Type III Repeat in Fibronectin Activates an Inflammatory Pathway in Dermal Fibroblasts. J Biol Chem (2010) 285:36255-9. doi: 10.1074/jbc.C110.176990

67. Kelsh RM, McKeown-Longo PJ. Topographical Changes in Extracellular Matrix: Activation of TLR4 Signaling and Solid Tumor Progression. Trends Cancer Res (2013) 9:1-13.

68. Han SW, Khuri FR, Roman J. Fibronectin Stimulates Non-Small Cell Lung Carcinoma Cell Growth Through Activation of Akt/mammalian Target of Rapamycin/S6 Kinase and Inactivation of LKB1/AMP-Activated Protein Kinase Signal Pathways. Cancer Res (2006) 66:315-23. doi: 10.1158/00085472.CAN-05-2367

69. Mori T, Ono K, Kariya Y, Ogawa T, Higashi S, Miyazaki K. Laminin-3B11, a Novel Vascular-Type Laminin Capable of Inducing Prominent Lamellipodial Protrusions in Microvascular Endothelial Cells. J Biol Chem (2010) 285:35068-78. doi: 10.1074/jbc.M110.146126

70. Miyazaki K. Laminin-5 (Laminin-332): Unique Biological Activity and Role in Tumor Growth and Invasion. Cancer Sci (2006) 97:91-8. doi: 10.1111/ j.1349-7006.2006.00150.x

71. An SJ, Lin QX, Chen ZH, Su J, Cheng H, Xie Z, et al. Combinations of Laminin 5 With PTEN, P-EGFR and P-Akt Define a Group of Distinct Molecular Subsets Indicative of Poor Prognosis in Patients With Non-Small Cell Lung Cancer. Exp Ther Med (2012) 4:226-30. doi: 10.3892/etm.2012.577

72. Stewart RL, West D, Wang C, Weiss HL, Gal T, Durbin EB, et al. Elevated Integrin $\alpha 6 \beta 4$ Expression is Associated With Venous Invasion and Decreased Overall Survival in Non-Small Cell Lung Cancer. Hum Pathol (2016) 54:174-83. doi: 10.1016/j.humpath.2016.04.003
73. Kim I, Kim HG, Kim H, Kim HH, Park SK, Uhm CS, et al. Hepatic Expression, Synthesis and Secretion of a Novel Fibrinogen/AngiopoietinRelated Protein That Prevents Endothelial-Cell Apoptosis. Biochem J (2000) 346:603-10. doi: 10.1042/0264-6021:3460603

74. Courtney M, Stoler M, Marder V, Haidaris P. Developmental Expression of mRNAs Encoding Platelet Proteins in Rat Megakaryocytes. Blood (1991) 77:560-8. doi: 10.1182/blood.v77.3.560.560

75. Sahni A, Simpson-Haidaris PJ, Sahni SK, Vaday GG, Francis CW. Fibrinogen Synthesized by Cancer Cells Augments the Proliferative Effect of Fibroblast Growth Factor-2 (FGF-2). J Thromb Haemost (2007) 6:176-83. doi: $10.1111 /$ j.1538-7836.2007.02808.x

76. Sahni A, Francis CW. Vascular Endothelial Growth Factor Binds to Fibrinogen and Fibrin and Stimulates Endothelial Cell Proliferation. Blood (2000) 96:3772-8. doi: 10.1182/blood.v96.12.3772

77. Guadiz G, Sporn LA, Simpson-Haidaris PJ. Thrombin CleavageIndependent Deposition of Fibrinogen in Extracellular Matrices. Blood (1997) 90:2644-53. doi: 10.1182/blood.v90.7.2644

78. Mosesson MW. Fibrinogen and Fibrin Structure and Functions. J Thromb Haemost (2005) 3:1894-904. doi: 10.1111/j.1538-7836.2005.01365.x

79. Shang Z, Niu X, Zhang K, Qiao Z, Liu S, Jiang X, et al. FGA Isoform as an Indicator of Targeted Therapy for EGFR Mutated Lung Adenocarcinoma. J Mol Med (2019) 97:1657-68. doi: 10.1007/s00109-019-01848-Z

80. Sun C, Gao W, Liu J, Cheng H, Hao J. FGL1 Regulates Acquired Resistance to Gefitinib by Inhibiting Apoptosis in Non-Small Cell Lung Cancer. Respir Res (2020) 21(1):210. doi: 10.1186/s12931-020-01477-y

81. Guan J, Xiao N, Qiu C, Li Q, Chen M, Zhang Y, et al. Fibrinogen Is Associated With EGFR Mutation Status and Lymphatic Metastasis in NonSmall Cell Lung Cancer. Oncol Lett (2019) 17:739-46. doi: 10.3892/ ol.2018.9652

82. Sun Z, Velázquez-Quesada I, Murdamoothoo D, Ahowesso C, Yilmaz A, Spenlé C, et al. Tenascin-C Increases Lung Metastasis by Impacting Blood Vessel Invasions. Matrix Biol (2019) 83:26-47. doi: 10.1016/j.matbio. 2019.07.001

83. Giblin SP, Midwood KS. Tenascin-C: Form Versus Function. Cell Adhes Migr (2015) 9:48-82. doi: 10.4161/19336918.2014.987587

84. Ruan K, Bao S, Ouyang G. The Multifaceted Role of Periostin in Tumorigenesis. Cell Mol Life Sci (2009) 66:2219-30. doi: 10.1007/s00018009-0013-7

85. Kudo Y, Siriwardena BSMS, Hatano H, Ogawa I, Takata T. Periostin: Novel Diagnostic and Therapeutic Target for Cancer. Histol Histopathol (2007) 22:1167-74. doi: 10.14670/HH-22.1167

86. Baril P, Gangeswaran R, Mahon PC, Caulee K, Kocher HM, Harada T, et al. Periostin Promotes Invasiveness and Resistance of Pancreatic Cancer Cells to Hypoxia-Induced Cell Death: Role of the $\beta 4$ Integrin and the PI3k Pathway. Oncogene (2007) 26:2082-94. doi: 10.1038/sj.onc.1210009

87. Bao S, Ouyang G, Bai X, Huang Z, Ma C, Liu M, et al. Periostin Potently Promotes Metastatic Growth of Colon Cancer by Augmenting Cell Survival via the Akt/PKB Pathway. Cancer Cell (2004) 5:329-39. doi: 10.1016/S15356108(04)00081-9

88. Hu WW, Chen PC, Chen JM, Wu YM, Liu PY, Lu CH, et al. Periostin Promotes Epithelial-Mesenchymal Transition via the MAPK/miR-381 Axis in Lung Cancer. Oncotarget (2017) 8:62248-60. doi: 10.18632/ oncotarget.19273

89. Ouyang G, Liu M, Ruan K, Song G, Mao Y, Bao S. Upregulated Expression of Periostin by Hypoxia in Non-Small-Cell Lung Cancer Cells Promotes Cell Survival via the Akt/PKB Pathway. Cancer Lett (2009) 281:213-9. doi: 10.1016/j.canlet.2009.02.030

90. Schvartz I, Seger D, Shaltiel S. Vitronectin. Int J Biochem Cell Biol (1999) 31:539-44. doi: 10.1016/S1357-2725(99)00005-9

91. Böger C, Kalthoff H, Goodman SL, Behrens HM, Röcken C. Integrins and Their Ligands are Expressed in non-Small Cell Lung Cancer But Not Correlated With Parameters of Disease Progression. Virchows Arch (2014) 464:69-78. doi: 10.1007/s00428-013-1506-1

92. Ricono JM, Huang M, Barnes LA, Lau SK, Weis SM, Schlaepfer DD, et al. Specific Cross-Talk Between Epidermal Growth Factor Receptor and Integrin $\alpha$ V $\beta 5$ Promotes Carcinoma Cell Invasion and Metastasis. Cancer Res (2009) 69:1383-91. doi: 10.1158/0008-5472.CAN-08-3612 
93. Kohfeldt E, Sasaki T, Göhring W, Timpl R. Nidogen-2: A New Basement Membrane Protein With Diverse Binding Properties. J Mol Biol (1998) 282:99-109. doi: 10.1006/jmbi.1998.2004

94. Miosge N, Holzhausen S, Zelent C, Sprysch P, Herken R. Nidogen-1 and Nidogen-2 are Found in Basement Membranes During Human Embryonic Development. Histochem J (2001) 33:523-30. doi: 10.1023/A:1014995523521

95. Geng J, Sun J, Lin Q, Gu J, Zhao Y, Zhang H, et al. Methylation Status of NEUROG2 and NID2 Improves the Diagnosis of Stage I NSCLC. Oncol Lett (2012) 3:901-6. doi: 10.3892/ol.2012.587

96. Mokkapati S, Bechtel M, Reibetanz M, Miosge N, Nischt R. Absence of the Basement Membrane Component Nidogen 2, But Not of Nidogen 1, Results in Increased Lung Metastasis in Mice. J Histochem Cytochem (2012) 60:2809. doi: $10.1369 / 0022155412436586$

97. Chai AWY, Cheung AKL, Dai W, Ko JMY, Ip JCY, Chan KW, et al. Metastasis-Suppressing NID2, an Epigenetically-Silenced Gene, in the Pathogenesis of Nasopharyngeal Carcinoma and Esophageal Squamous Cell Carcinoma. Oncotarget (2016) 7:78859-71. doi: 10.18632/ oncotarget.12889

98. Iozzo RV, Sanderson RD. Proteoglycans in Cancer Biology, Tumour Microenvironment and Angiogenesis. J Cell Mol Med (2011) 15:1013-31. doi: $10.1111 / j .1582-4934.2010 .01236 . x$

99. Gassar ES, Ibrahim SA, Götte M. Heparan Sulfate Proteoglycans in Cancer Therapy. In: Pavã M. (eds) Glycans in Diseases and Therapeutics. Springer, Berlin, Heidelberg: Biology of Extracellular Matrix. doi: 10.1007/978-3-64216833-8_6

100. Guo JY, Chiu CH, Wang MJ, Li FA, Chen JY. Proteoglycan Serglycin Promotes non-Small Cell Lung Cancer Cell Migration Through the Interaction of its Glycosaminoglycans With CD44. J BioMed Sci (2020) 27:2. doi: 10.1186/s12929-019-0600-3

101. Nackaerts K, Verbeken E, Deneffe G, Vanderschueren B, Demedts M, David G. Heparan Sulfate Proteoglycan Expression in Human Lung-Cancer Cells. Int J Cancer (1997) 74:335-45. doi: 10.1002/(SICI)1097-0215(19970620) 74:3<335::AID-IJC18>3.0.CO;2-A

102. Pirinen R, Leinonen T, Böhm J, Johansson R, Ropponen K, Kumpulainen E, et al. Versican in Nonsmall Cell Lung Cancer: Relation to Hyaluronan, Clinicopathologic Factors, and Prognosis. Hum Pathol (2005) 36:44-50. doi: 10.1016/j.humpath.2004.10.010

103. Fernandez-Madrid F, Karvonen RL, Kraut MJ, Czelusniak B, Ager JW. Autoimmunity to Collagen in Human Lung Cancer. Cancer Res (1996) 56 (1):121-6.

104. Liang S, Xu JF, Cao WJ, Li HP, Hu CP. Human Decorin Regulates Proliferation and Migration of Human Lung Cancer A549 Cells. Chin Med J (Engl) (2013) 126:4736-41. doi: 10.3760/cma.j.issn.0366-6999.20130207

105. Nikitovic D, Papoutsidakis A, Karamanos NK, Tzanakakis GN. Lumican Affects Tumor Cell Functions, Tumor-ECM Interactions, Angiogenesis and Inflammatory Response. Matrix Biol (2014) 35:206-14. doi: 10.1016/ j.matbio.2013.09.003

106. Shah L, Walter KL, Borczuk AC, Kawut SM, Sonett JR, Gorenstein LA, et al. Expression of Syndecan-1 and Expression of Epidermal Growth Factor Receptor are Associated With Survival in Patients With Nonsmall Cell Lung Carcinoma. Cancer (2004) 101:1632-8. doi: 10.1002/cncr.20542

107. Reka AK, Chen G, Jones RC, Amunugama R, Kim S, Karnovsky A, et al. Epithelial-Mesenchymal Transition-Associated Secretory Phenotype Predicts Survival in Lung Cancer Patients. Carcinogenesis (2014) 35:1292300. doi: 10.1093/carcin/bgu041

108. Yang YC, Pan KF, Lee WJ, Chang JH, Tan P, Gu CC, et al. Circulating Proteoglycan Endocan Mediates EGFR-Driven Progression of non-Small Cell Lung Cancer. Cancer Res (2020) 80:3292-304. doi: 10.1158/00085472.CAN-20-0005

109. Fei X, Zhang J, Zhao Y, Sun M, Zhao H, Li S. MiR-96 Promotes Invasion and Metastasis by Targeting GPC3 in non-Small Cell Lung Cancer Cells. Oncol Lett (2018) 15:9081-6. doi: 10.3892/ol.2018.8507

110. Bernfield M, Götte M, Park PW, Reizes O, Fitzgerald ML, Lincecum J, et al. Functions of Cell Surface Heparan Sulfate Proteoglycans. Annu Rev Biochem (1999) 68:729-77. doi: 10.1146/annurev.biochem.68.1.729

111. Capurro M, Martin T, Shi W, Filmus J. Glypican-3 Binds to Frizzled and Plays a Direct Role in the Stimulation of Canonical Wnt Signaling. J Cell Sci 127(Pt 7):1565-75. doi: 10.1242/jcs.140871
112. Häcker U, Nybakken K, Perrimon N. Heparan Sulphate Proteoglycans: The Sweet Side of Development. Nat Rev Mol Cell Biol (2005) 6:530-41. doi: $10.1038 / \mathrm{nrm} 1681$

113. Yuan S, Yu Z, Liu Q, Zhang M, Xiang Y, Wu N, et al. GPC5, a Novel Epigenetically Silenced Tumor Suppressor, Inhibits Tumor Growth by Suppressing Wnt/ $\beta$-Catenin Signaling in Lung Adenocarcinoma. Oncogene (2016) 35:6120-31. doi: 10.1038/onc.2016.149

114. Li Y, Sheu CC, Ye Y, de Andrade M, Wang L, Chang SC, et al. Genetic Variants and Risk of Lung Cancer in Never Smokers: A Genome-Wide Association Study. Lancet Oncol (2010) 11:321-30. doi: 10.1016/S1470-2045 (10)70042-5

115. Li Y, Miao L, Cai H, Ding J, Xiao Y, Yang J, et al. The Overexpression of Glypican-5 Promotes Cancer Cell Migration and is Associated With Shorter Overall Survival in non-Small Cell Lung Cancer. Oncol Lett (2013) 6:156572. doi: 10.3892/ol.2013.1622

116. Cai Z, Grobe K, Zhang X. Role of Heparan Sulfate Proteoglycans in Optic Disc and Stalk Morphogenesis. Dev Dyn (2014) 243:1310-6. doi: 10.1002/ dvdy. 24142

117. Ellina MI, Bouris P, Aletras AJ, Theocharis AD, Kletsas D, Karamanos NK. EGFR and HER2 Exert Distinct Roles on Colon Cancer Cell Functional Properties and Expression of Matrix Macromolecules. Biochim Biophys Acta - Gen Subj (2014) 1840:2651-61. doi: 10.1016/j.bbagen.2014.04.019

118. Tsonis AI, Afratis N, Gialeli C, Ellina MI, Piperigkou Z, Skandalis SS, et al. Evaluation of the Coordinated Actions of Estrogen Receptors With Epidermal Growth Factor Receptor and Insulin-Like Growth Factor Receptor in the Expression of Cell Surface Heparan Sulfate Proteoglycans and Cell Motility in Breast Cancer Cells. FEBS J (2013) 280:2248-59. doi: $10.1111 /$ febs.12162

119. Harada E, Serada S, Fujimoto M, Takahashi Y, Takahashi T, Hara H, et al. Glypican-1 Targeted Antibody-Based Therapy Induces Preclinical Antitumor Activity Against Esophageal Squamous Cell Carcinoma. Oncotarget (2017) 8:24741-52. doi: 10.18632/oncotarget.15799

120. Qian JY, Tan YL, Zhang Y, Yang YF, Li XQ. Prognostic Value of Glypican-1 for Patients With Advanced Pancreatic Cancer Following Regional IntraArterial Chemotherapy. Oncol Lett (2018) 16:1253-8. doi: 10.3892/ ol.2018.8701

121. Toyoshima E, Ohsaki Y, Nishigaki Y, Fujimoto Y, Kohgo Y, Kikuchi K. Expression of Syndecan-1 is Common in Human Lung Cancers Independent of Expression of Epidermal Growth Factor Receptor. Lung Cancer (2001) 31:193-202. doi: 10.1016/S0169-5002(00)00184-7

122. Ibrahim SA, Hassan H, Reinbold R, Espinoza-Sanchez NA, Greve B, Götte M. Role of Syndecan-1 in Cancer Stem Cells. In: Götte M, Forsberg-Nilsson K. (eds) Proteoglycans in Stem Cells. Biology of Extracellular Matrix, vol 9. Springer, Cham. doi: 10.1007/978-3-030-73453-4_12

123. Katakam SK, Tria V, Sim W-C, Yip GW, Molgora S, Karnavas T, et al. The Heparan Sulfate Proteoglycan Syndecan-1 Regulates Colon Cancer Stem Cell Function via a Focal Adhesion Kinase-Wnt Signaling Axis. FEBS J (2021) 288:486-506. doi: 10.1111/FEBS.15356

124. Hassan H, Greve B, Kiesel L, Ibrahim S, Götte M. Syndecan-1 Modulates IL6- and Beta-Integrin- Dependent Functions in Breast Cancer Cell Adhesion and Migration. Exp Clin Endocrinol Diabetes (2013) 121:OP5_31. doi: $10.1055 / \mathrm{S}-0033-1336639$

125. Nassar E, Hassan N, El-Ghonaimy EA, Hassan H, Abdullah MS, Rottke TV, et al. Syndecan-1 Promotes Angiogenesis in Triple-Negative Breast Cancer Through the Prognostically Relevant Tissue Factor Pathway and Additional Angiogenic Routes. Cancers (2021) 13:2318. doi: 10.3390/ CANCERS13102318

126. Ibrahim SA, Gadalla R, El-Ghonaimy EA, Samir O, Mohamed HT, Hassan $\mathrm{H}$, et al. Syndecan-1 is a Novel Molecular Marker for Triple Negative Inflammatory Breast Cancer and Modulates the Cancer Stem Cell Phenotype via the IL-6/STAT3, Notch and EGFR Signaling Pathways. Mol Cancer (2017) 16(1):57. doi: 10.1186/s12943-017-0621-z

127. Ibrahim SA, Yip GW, Stock C, Pan J-W, Neubauer C, Poeter M, et al. Targeting of Syndecan-1 by microRNA miR-10b Promotes Breast Cancer Cell Motility and Invasiveness via a Rho-GTPase- and E-Cadherin-Dependent Mechanism. Int J Cancer (2012) 131:E884-96. doi: 10.1002/IJC.27629

128. Nikolova V, Koo C-Y, Ibrahim SA, Wang Z, Spillmann D, Dreier R, et al. Differential Roles for Membrane-Bound and Soluble Syndecan-1 (CD138) in 
Breast Cancer Progression. Carcinogenesis (2009) 30:397-407. doi: 10.1093/ CARCIN/BGP001

129. Ruoslahti E, Yamaguchi Y. Proteoglycans as Modulators of Growth Factor Activities. Cell (1991) 64:867-9. doi: 10.1016/0092-8674(91)90308-L

130. Aviezer D, Yayon A. Heparin-Dependent Binding and Autophosphorylation of Epidermal Growth Factor (EGF) Receptor by Heparin-Binding EGF-Like Growth Factor But Not by EGF. Proc Natl Acad Sci U.S.A. (1994) 91:121737. doi: $10.1073 /$ pnas.91.25.12173

131. Zhu YC, Xu CW, Zhang QX, Wang WX, Lei L, Zhuang W. Syndecan 4-CRos Oncogene 1 Fusion as a Mechanism of Acquired Resistance in Epidermal Growth Factor Receptor Mutant Lung Adenocarcinoma. Chin Med J (Engl) (2019) 132:3015-7. doi: 10.1097/CM9.0000000000000555

132. Zeng L, Yang N, Zhang Y. GOPC-ROS1 Rearrangement as an Acquired Resistance Mechanism to Osimertinib and Responding to Crizotinib Combined Treatments in Lung Adenocarcinoma. J Thorac Oncol (2018) 13:e114-6. doi: 10.1016/j.jtho.2018.02.005

133. Mulshine JL, Chow G, Tauler J. Cytokines and Growth Factors Stimulate Hyaluronan Production: Role of Hyaluronan in Epithelial to MesenchymalLike Transition in non-Small Cell Lung Cancer. J BioMed Biotechnol (2010) 2010:485468. doi: 10.1155/2010/485468

134. Hiraga T, Ito S, Nakamura H. Cancer Stem-Like Cell Marker CD44 Promotes Bone Metastases by Enhancing Tumorigenicity, Cell Motility, and Hyaluronan Production. Cancer Res (2013) 73:4112-22. doi: 10.1158/ 0008-5472.CAN-12-3801

135. Hiscox S, Baruha B, Smith C, Bellerby R, Goddard L, Jordan N, et al. Overexpression of CD44 Accompanies Acquired Tamoxifen Resistance in MCF7 Cells and Augments Their Sensitivity to the Stromal Factors, Heregulin and Hyaluronan. BMC Cancer (2012) 12:458. doi: 10.1186/ 1471-2407-12-458

136. Song JM, Im J, Nho RS, Han YH, Upadhyaya P, Kassie F. HyaluronanCD44/RHAMM Interaction-Dependent Cell Proliferation and Survival in Lung Cancer Cells. Mol Carcinog (2019) 58:321-33. doi: 10.1002/mc.22930

137. Song JM, Molla K, Anandharaj A, Cornax I, Gerard O'Sullivan M, Kirtane AR, et al. Triptolide Suppresses the In Vitro and In Vivo Growth of Lung Cancer Cells by Targeting Hyaluronan-CD44/RHAMM Signaling. Oncotarget (2017) 8:26927-40. doi: 10.18632/oncotarget.15879

138. Talekar M, Trivedi M, Shah P, Ouyang Q, Oka A, Gandham S, et al. Combination Wt-P53 and MicroRNA-125b Transfection in a Genetically Engineered Lung Cancer Model Using Dual CD44/EGFR-Targeting Nanoparticles. Mol Ther (2016) 24:759-69. doi: 10.1038/mt.2015.225

139. Li L, Qi L, Liang Z, Song W, Liu Y, Wang Y, et al. Transforming Growth Factor- $\beta 1$ Induces EMT by the Transactivation of Epidermal Growth Factor Signaling Through HA/CD44 in Lung and Breast Cancer Cells. Int J Mol Med (2015) 36:113-22. doi: 10.3892/ijmm.2015.2222

140. Frantz C, Stewart KM, Weaver VM. The Extracellular Matrix at a Glance. J Cell Sci (2010) 123:4195-200. doi: 10.1242/jcs.023820

141. Nissen NI, Karsdal M, Willumsen N. Collagens and Cancer Associated Fibroblasts in the Reactive Stroma and its Relation to Cancer Biology. J Exp Clin Cancer Res (2019) 38(1):115. doi: 10.1186/s13046-019-1110-6

142. O’Reilly MS, Boehm T, Shing Y, Fukai N, Vasios G, Lane WS, et al. Endostatin: An Endogenous Inhibitor of Angiogenesis and Tumor Growth. Cell (1997) 88:277-85. doi: 10.1016/S0092-8674(00)81848-6

143. Qiu S, Deng L, Liao X, Nie L, Qi F, Jin K, et al. Tumor-Associated Macrophages Promote Bladder Tumor Growth Through PI3K/AKT Signal Induced by Collagen. Cancer Sci (2019) 110:2110-8. doi: 10.1111/cas.14078

144. Sampath Narayanan A, Page RC. Synthesis of Type V Collagen by Fibroblasts Derived From Normal, Inflamed and Hyperplastic Human Connective Tissues. Top Catal (1985) 5:297-304. doi: 10.1016/S0174-173X (85)80019-4

145. Zou Y, Zhang R-Z, Sabatelli P, Chu M-L, Bönnemann CG. Muscle Interstitial Fibroblasts Are the Main Source of Collagen VI Synthesis in Skeletal Muscle: Implications for Congenital Muscular Dystrophy Types Ullrich and Bethlem. J Neuropathol Exp Neurol (2008) 67:144-54. doi: 10.1097/ nen.0b013e3181634ef7

146. Ricard-Blum S. The Collagen Family. Cold Spring Harb Perspect Biol (2011) 3:1-19. doi: 10.1101/cshperspect.a004978

147. Xu Y, Zhao Y, Su B, Chen Y, Zhou C. Expression of Collagen IV, Fibronectin, Laminin in non-Small Cell Lung Cancer and its Correlation With
Chemosensitivities and Apoptosis. Chinese-German J Clin Oncol (2006) 5:58-62. doi: 10.1007/s10330-005-0440-3

148. Kalluri R. The Biology and Function of Fibroblasts in Cancer. Nat Rev Cancer (2016) 16:582-98. doi: 10.1038/nrc.2016.73

149. Kalluri R, Zeisberg M. Fibroblasts in Cancer. Nat Rev Cancer (2006) 6:392401. doi: $10.1038 / \mathrm{nrc} 1877$

150. Pankova D, Chen Y, Terajima M, Schliekelman MJ, Baird BN, Fahrenholtz $\mathrm{M}$, et al. Cancer-Associated Fibroblasts Induce a Collagen Cross-Link Switch in Tumor Stroma. Mol Cancer Res (2016) 14:287-95. doi: 10.1158/15417786.MCR-15-0307

151. Pickup MW, Mouw JK, Weaver VM. The Extracellular Matrix Modulates the Hallmarks of Cancer. EMBO Rep (2014) 15:1243-53. doi: 10.15252/ embr.201439246

152. Bager CL, Willumsen N, Leeming DJ, Smith V, Karsdal MA, Dornan D, et al. Collagen Degradation Products Measured in Serum can Separate Ovarian and Breast Cancer Patients From Healthy Controls: A Preliminary Study. Cancer Biomarkers (2015) 15:783-8. doi: 10.3233/CBM-150520

153. Willumsen N, Bager CL, Leeming DJ, Smith V, Christiansen C, Karsdal MA, et al. Serum Biomarkers Reflecting Specific Tumor Tissue Remodeling Processes are Valuable Diagnostic Tools for Lung Cancer. Cancer Med (2014) 3:1136-45. doi: 10.1002/cam4.303

154. Leeming DJ, Koizumi M, Qvist P, Barkholt V, Zhang C, Henriksen K, et al. Serum N-Terminal Propeptide of Collagen Type I is Associated With the Number of Bone Metastases in Breast and Prostate Cancer and Correlates to Other Bone Related Markers. biomark Cancer (2011) 3:15-23. doi: 10.4137/ BIC.S6484

155. Li J, Li X, Lan T, Qi C, He X. Type I Collagen Secreted by Lung Cancer Cells Promotes Cancer Cell Growth in a Three- Dimensional Culture System PubMed. Nan Fang Yi Ke Da Xue Xue Bao (2014) 34(8):1129-34.

156. Xu S, Xu H, Wang W, Li S, Li H, Li T, et al. The Role of Collagen in Cancer: From Bench to Bedside. J Transl Med (2019) 17(1):309. doi: 10.1186/s12967019-2058-1

157. Bonnans C, Chou J, Werb Z. Remodelling the Extracellular Matrix in Development and Disease. Nat Rev Mol Cell Biol (2014) 15:786-801. doi: $10.1038 / \mathrm{nrm} 3904$

158. Mason SD, Joyce JA. Proteolytic Networks in Cancer. Trends Cell Biol (2011) 21:228-37. doi: 10.1016/j.tcb.2010.12.002

159. Chen Y, Terajima M, Yang Y, Sun L, Ahn YH, Pankova D, et al. Lysyl Hydroxylase 2 Induces a Collagen Cross-Link Switch in Tumor Stroma. J Clin Invest (2015) 125:1147-62. doi: 10.1172/JCI74725

160. Chen Y, Guo H, Terajima M, Banerjee P, Liu X, Yu J, et al. Lysyl Hydroxylase 2 is Secreted by Tumor Cells and can Modify Collagen in the Extracellular Space. J Biol Chem (2016) 291:25799-808. doi: 10.1074/jbc.M116.759803

161. Du H, Chen Y, Hou X, Huang Y, Wei X, Yu X, et al. PLOD2 Regulated by Transcription Factor FOXA1 Promotes Metastasis in NSCLC. Cell Death Dis (2017) 8:e3143. doi: 10.1038/cddis.2017.553

162. Humphries MJ. Integrin Cell Adhesion Receptors and the Concept of Agonism. Trends Pharmacol Sci (2000) 21:29-32. doi: 10.1016/S0165-6147 (99)01410-8

163. Barczyk M, Carracedo S, Gullberg D. Integrins. Cell Tissue Res (2010) 339:269-80. doi: 10.1007/s00441-009-0834-6

164. Ruoslahti E. RGD AND OTHER RECOGNITION SEQUENCES FOR INTEGRINS. Annu Rev Cell Dev Biol (1996) 12:697-715. doi: 10.1146/ annurev.cellbio.12.1.697

165. Zhao X, Guan JL. Focal Adhesion Kinase and its Signaling Pathways in Cell Migration and Angiogenesis. Adv Drug Delivery Rev (2011) 63:610-5. doi: 10.1016/j.addr.2010.11.001

166. Mitra SK, Schlaepfer DD. Integrin-Regulated FAK-Src Signaling in Normal and Cancer Cells. Curr Opin Cell Biol (2006) 18:516-23. doi: 10.1016/ j.ceb.2006.08.011

167. Giancotti FG, Ruoslahti E. Integrin Signaling. Sci (80- ) (1999) 285:1028-32. doi: 10.1126/science. 285.5430 .1028

168. Cybulsky AV, McTavish AJ, Cyr MD. Extracellular Matrix Modulates Epidermal Growth Factor Receptor Activation in Rat Glomerular Epithelial Cells. J Clin Invest (1994) 94:68-78. doi: 10.1172/JCI117350

169. Miyamoto S, Teramoto H, Gutkind JS, Yamada KM. Integrins can Collaborate With Growth Factors for Phosphorylation of Receptor Tyrosine Kinases and MAP Kinase Activation: Roles of Integrin 
Aggregation and Occupancy of Receptors. J Cell Biol (1996) 135:1633-42. doi: $10.1083 /$ jcb.135.6.1633

170. Moro L, Venturino M, Bozzo C, Silengo L, Altruda F, Beguinot L, et al. Integrins Induce Activation of EGF Receptor: Role in MAP Kinase Induction and Adhesion-Dependent Cell Survival. EMBO J (1998) 17:6622-32. doi: $10.1093 / \mathrm{emboj} / 17.22 .6622$

171. Li J, Lin ML, Wiepz GJ, Guadarrama AG, Bertics PJ. Integrin-Mediated Migration of Murine B82L Fibroblasts is Dependent on the Expression of an Intact Epidermal Growth Factor Receptor. J Biol Chem (1999) 274:11209-19. doi: $10.1074 /$ jbc.274.16.11209

172. Desgrosellier JS, Cheresh DA. Integrins in Cancer: Biological Implications and Therapeutic Opportunities. Nat Rev Cancer (2010) 10:9-22. doi: $10.1038 / \mathrm{nrc} 2748$

173. Bill HM, Knudsen B, Moores SL, Muthuswamy SK, Rao VR, Brugge JS, et al. Epidermal Growth Factor Receptor-Dependent Regulation of IntegrinMediated Signaling and Cell Cycle Entry in Epithelial Cells. Mol Cell Biol (2004) 24:8586-99. doi: 10.1128/mcb.24.19.8586-8599.2004

174. Ivaska J, Heino J. Cooperation Between Integrins and Growth Factor Receptors in Signaling and Endocytosis. Annu Rev Cell Dev Biol (2011) 27:291-320. doi: 10.1146/annurev-cellbio-092910-154017

175. Mariotti A, Kedeshian PA, Dans M, Curatola AM, Gagnoux-Palacios L, Giancotti FG. EGF-R Signaling Through Fyn Kinase Disrupts the Function of Integrin $\alpha 6 \beta 4$ at Hemidesmosomes: Role in Epithelial Cell Migration and Carcinoma Invasion. J Cell Biol (2001) 155:447-57. doi: 10.1083/ jcb.200105017

176. Moro L, Dolce L, Cabodi S, Bergatto E, Erba EB, Smeriglio M, et al. Integrin-Induced Epidermal Growth Factor (EGF) Receptor Activation Requires C-Src and p130Cas and Leads to Phosphorylation of Specific EGF Receptor Tyrosines. J Biol Chem (2002) 277:9405-14. doi: 10.1074/ jbc.M109101200

177. Morello V, Cabodi S, Sigismund S, Camacho-Leal MP, Repetto D, Volante $\mathrm{M}$, et al. $\beta 1$ Integrin Controls EGFR Signaling and Tumorigenic Properties of Lung Cancer Cells. Oncogene (2011) 30:4087-96. doi: 10.1038/ ONC.2011.107

178. Kondo S, Iwata S, Yamada T, Inoue Y, Ichihara H, Kichikawa Y, et al. Impact of the Integrin Signaling Adaptor Protein NEDD9 on Prognosis and Metastatic Behavior of Human Lung Cancer. Clin Cancer Res (2012) 18:6326-38. doi: 10.1158/1078-0432.CCR-11-2162

179. Zhu J, Cai T, Zhou J, Du W, Zeng Y, Liu T, et al. CD151 Drives Cancer Progression Depending on Integrin $\alpha 3 \beta 1$ Through EGFR Signaling in nonSmall Cell Lung Cancer. J Exp Clin Cancer Res (2021) 40(1):192. doi: 10.1186/S13046-021-01998-4

180. Karamanos NK, Theocharis AD, Neill T, Iozzo RV. Matrix Modeling and Remodeling: A Biological Interplay Regulating Tissue Homeostasis and Diseases. Matrix Biol (2019) 75-76:1-11. doi: 10.1016/J.MATBIO. 2018.08.007

181. Iozzo RV, Gubbiotti MA. Extracellular Matrix: The Driving Force of Mammalian Diseases. Matrix Biol (2018) 71-72:1-9. doi: 10.1016/ J.MATBIO.2018.03.023

182. Borgoño CA, Diamandis EP. The Emerging Roles of Human Tissue Kallikreins in Cancer. Nat Rev Cancer (2004) 4:876-90. doi: 10.1038/ NRC1474

183. Yang X, Zhang X, Wu R, Huang Q, Jiang Y, Qin J, et al. DPPIV Promotes Endometrial Carcinoma Cell Proliferation, Invasion and Tumorigenesis. Oncotarget (2017) 8:8679-92. doi: 10.18632/ONCOTARGET.14412

184. Deryugina E, Carré A, Ardi V, Muramatsu T, Schmidt J, Pham C, et al. Neutrophil Elastase Facilitates Tumor Cell Intravasation and Early Metastatic Events. iScience (2020) 23(12):101799. doi: 10.1016/ J.ISCI.2020.101799

185. Piperigkou Z, Manou D, Karamanou K, Theocharis AD. Strategies to Target Matrix Metalloproteinases as Therapeutic Approach in Cancer. Methods Mol Biol (2018) 1731:325-48. doi: 10.1007/978-1-4939-7595-2_27

186. Visse R, Nagase H. Matrix Metalloproteinases and Tissue Inhibitors of Metalloproteinases: Structure, Function, and Biochemistry. Circ Res (2003) 92:827-39. doi: 10.1161/01.RES.0000070112.80711.3D

187. Verma RP, Hansch C. Matrix Metalloproteinases (MMPs): ChemicalBiological Functions and (Q)SARs. Bioorg Med Chem (2007) 15:2223-68. doi: 10.1016/J.BMC.2007.01.011
188. Gialeli C, Theocharis AD, Karamanos NK. Roles of Matrix Metalloproteinases in Cancer Progression and Their Pharmacological Targeting. FEBS J (2011) 278:16-27. doi: 10.1111/J.1742-4658.2010.07919.X

189. Cathcart J, Pulkoski-Gross A, Cao J. Targeting Matrix Metalloproteinases in Cancer: Bringing New Life to Old Ideas. Genes Dis (2015) 2:26-34. doi: 10.1016/j.gendis.2014.12.002

190. Nagaset H, Woessner JF. Matrix Metalloproteinases. J Biol Chem (1999) 274:21491-4. doi: 10.1074/jbc.274.31.21491

191. Stawowczyk M, Wellenstein MD, Lee SB, Yomtoubian S, Durrans A, Choi H, et al. Matrix Metalloproteinase 14 Promotes Lung Cancer by Cleavage of Heparin-Binding EGF-Like Growth Factor. Neoplasia (United States) (2017) 19:55-64. doi: 10.1016/j.neo.2016.11.005

192. Merchant N, Nagaraju GP, Rajitha B, Lammata S, Jella KK, S.Buchwald Z, et al. Matrix Metalloproteinases: Their Functional Role in Lung Cancer. Carcinogenesis (2017) 38:766-80. doi: 10.1093/carcin/bgx063

193. Nerenberg PS, Salsas-Escat R, Stultz CM. Collagen-A Necessary Accomplice in the Metastatic Process. Cancer Genomics Proteomics (2007) 4(5):319-28.

194. Chen P, Cescon M, Bonaldo P. Collagen VI in Cancer and Its Biological Mechanisms. Trends Mol Med (2013) 19(7):410-7. doi: 10.1016/ j.molmed.2013.04.001

195. Kalluri R. Basement Membranes: Structure, Assembly and Role in Tumour Angiogenesis. Nat Rev Cancer (2013) 3(6):422-33. doi: 10.1038/nrc1094

196. Cox G, Jones JL, O’byrne KJ. Matrix Metalloproteinase 9 and the Epidermal Growth Factor Signal Pathway in Operable Non-Small Cell Lung Cancer 1. Clin Cancer Res (2000) 6(6):2349-55.

197. Ishii G, Ochiai A, Neri S. Phenotypic and Functional Heterogeneity of Cancer-Associated Fibroblast Within the Tumor Microenvironment. Adv Drug Delivery Rev (2016) 99:186-96. doi: 10.1016/J.ADDR.2015.07.007

198. Yoshida T, Ishii G, Goto K, Neri S, Hashimoto H, Yoh K, et al. PodoplaninPositive Cancer-Associated Fibroblasts in the Tumor Microenvironment Induce Primary Resistance to EGFR-TKIs in Lung Adenocarcinoma With EGFR Mutation. Clin Cancer Res (2015) 21:642-51. doi: 10.1158/10780432.CCR-14-0846

199. Provenzano PP, Inman DR, Eliceiri KW, Knittel JG, Yan L, Rueden CT, et al. Collagen Density Promotes Mammary Tumor Initiation and Progression. BMC Med (2008) 6:11. doi: 10.1186/1741-7015-6-11

200. Kakkad SM, Solaiyappan M, O’Rourke B, Stasinopoulos I, Ackerstaff E, Raman V, et al. Hypoxic Tumor Microenvironments Reduce Collagen I Fiber Density. Neoplasia (2010) 12:608. doi: 10.1593/NEO.10344

201. Kanda R, Kawahara A, Watari K, Murakami Y, Sonoda K, Maeda M, et al. Erlotinib Resistance in Lung Cancer Cells Mediated by Integrin $\beta 1 / \mathrm{Src} / \mathrm{Akt}$ Driven Bypass Signaling. Cancer Res (2013) 73:6243-53. doi: 10.1158/00085472.CAN-12-4502

202. Yamazaki S, Su Y, Maruyama A, Makinoshima H, Suzuki J, Tsuboi M, et al. Uptake of Collagen Type I via Macropinocytosis Cause mTOR Activation and Anti-Cancer Drug Resistance. Biochem Biophys Res Commun (2020) 526:191-8. doi: 10.1016/j.bbrc.2020.03.067

203. Ishiguro Y, Ishiguro H, Miyamoto H. Epidermal Growth Factor Receptor Tyrosine Kinase Inhibition Up-Regulates Interleukin-6 in Cancer Cells and Induces Subsequent Development of Interstitial Pneumonia. Oncotarget (2013) 4:550-9. doi: 10.18632/oncotarget.939

204. Shintani Y, Maeda M, Chaika N, Johnson KR, Wheelock MJ. Collagen I Promotes Epithelial-to-Mesenchymal Transition in Lung Cancer Cells via Transforming Growth Factor- $\beta$ Signaling. Am J Respir Cell Mol Biol (2008) 38:95-104. doi: 10.1165/rcmb.2007-0071OC

205. Gilles C, Polette M, Seiki M, Birembaut P, Thompson EW. Implication of Collagen Type I-Induced Membrane-Type 1-Matrix Metalloproteinase Expression and Matrix Metalloproteinase-2 Activation in the Metastatic Progression of Breast Carcinoma. Lab Investig (1997) 76:651-60.

206. Yamazaki S, Higuchi Y, Ishibashi M, Hashimoto H, Yasunaga M, Matsumura $\mathrm{Y}$, et al. Collagen Type I Induces EGFR-TKI Resistance in EGFR-Mutated Cancer Cells by mTOR Activation Through Akt-Independent Pathway. Cancer Sci (2018) 109:2063-73. doi: 10.1111/cas.13624

207. Finicle BT, Jayashankar V, Edinger AL. Nutrient Scavenging in Cancer. Nat Rev Cancer (2018) 18:619-33. doi: 10.1038/S41568-018-0048-X

208. Ha KD, Bidlingmaier SM, Liu B. Macropinocytosis Exploitation by Cancers and Cancer Therapeutics. Front Physiol (2016) 7:381. doi: 10.3389/ FPHYS.2016.00381 
209. Huber MA, Kraut N, Beug H. Molecular Requirements for EpithelialMesenchymal Transition During Tumor Progression. Curr Opin Cell Biol (2005) 17:548-58. doi: 10.1016/j.ceb.2005.08.001

210. Thomson S, Buck E, Petti F, Griffin G, Brown E, Ramnarine N, et al. Epithelial to Mesenchymal Transition is a Determinant of Sensitivity of NonSmall-Cell Lung Carcinoma Cell Lines and Xenografts to Epidermal Growth Factor Receptor Inhibition. Cancer Res (2005) 65:9455-62. doi: 10.1158/ 0008-5472.CAN-05-1058

211. Suda K, Tomizawa K, Fujii M, Murakami H, Osada H, Maehara Y, et al. Epithelial to Mesenchymal Transition in an Epidermal Growth Factor Receptor-Mutant Lung Cancer Cell Line With Acquired Resistance to Erlotinib. J Thorac Oncol (2011) 6:1152-61. doi: 10.1097/JTO. 0b013e318216ee52

212. Mahmood MQ, Ward C, Muller HK, Sohal SS, Walters EH. Epithelial Mesenchymal Transition (EMT) and non-Small Cell Lung Cancer (NSCLC): A Mutual Association With Airway Disease. Med Oncol (2017) 34(3):45. doi: 10.1007/s12032-017-0900-y

213. Kharbanda A, Rajabi H, Jin C, Tchaicha J, Kikuchi E, Wong KK, et al. Targeting the Oncogenic MUC1-C Protein Inhibits Mutant EGFR-Mediated Signaling and Survival in non-Small Cell Lung Cancer Cells. Clin Cancer Res (2014) 20:5423-34. doi: 10.1158/1078-0432.CCR-13-3168

214. Karachaliou N, Cardona AF, Bracht JWP, Aldeguer E, Drozdowskyj A, Fernandez-Bruno M, et al. Integrin-Linked Kinase (ILK) and Src Homology 2 Domain-Containing Phosphatase 2 (SHP2): Novel Targets in EGFRMutation Positive non-Small Cell Lung Cancer (NSCLC). EBioMedicine (2019) 39:207-14. doi: 10.1016/J.EBIOM.2018.11.036

215. Wang C, Wang T, Lv D, Li L, Yue J, Chen HZ, et al. Acquired Resistance to EGFR TKIs Mediated by Tgf $\beta 1 /$ Integrin $\beta 3$ Signaling in EGFR-Mutant Lung Cancer. Mol Cancer Ther (2019) 18:2357-67. doi: 10.1158/1535-7163.MCT19-0181
216. Bernardes N, Abreu S, Carvalho FA, Fernandes F, Santos NC, Fialho AM. Modulation of Membrane Properties of Lung Cancer Cells by Azurin Enhances the Sensitivity to EGFR-Targeted Therapy and Decreased $\beta 1$ Integrin-Mediated Adhesion. Cell Cycle (2016) 15:1415-24. doi: 10.1080/ 15384101.2016.1172147

217. Li X, Ishihara S, Yasuda M, Nishioka T, Mizutani T, Ishikawa M, et al. Lung Cancer Cells That Survive Ionizing Radiation Show Increased Integrin $\alpha 2 \beta 1$ and EGFR-Dependent Invasiveness. PLoS One (2013) 8(8):e70905. doi: 10.1371/journal.pone.0070905

218. He F, Wang Y, Cai W, Li M, Dong L. Reversal of EGFR Inhibitors' Resistance by Co-Delivering EGFR and Integrin $\alpha v \beta 3$ Inhibitors With Nanoparticles in non-Small Cell Lung Cancer. Biosci Rep (2019) 39(8):BSR20181259. doi: 10.1042/BSR20181259

Conflict of Interest: The authors declare that the research was conducted in the absence of any commercial or financial relationships that could be construed as a potential conflict of interest.

Publisher's Note: All claims expressed in this article are solely those of the authors and do not necessarily represent those of their affiliated organizations, or those of the publisher, the editors and the reviewers. Any product that may be evaluated in this article, or claim that may be made by its manufacturer, is not guaranteed or endorsed by the publisher.

Copyright (C) 2021 Hassanein, Abdel-Mawgood and Ibrahim. This is an open-access article distributed under the terms of the Creative Commons Attribution License (CC BY). The use, distribution or reproduction in other forums is permitted, provided the original author(s) and the copyright owner(s) are credited and that the original publication in this journal is cited, in accordance with accepted academic practice. No use, distribution or reproduction is permitted which does not comply with these terms. 


\section{GLOSSARY}

\begin{tabular}{|c|c|}
\hline ADC & Adenocarcinoma \\
\hline AKT & Protein Kinase B \\
\hline ALK & Anaplastic Lymphoma Kinase \\
\hline AMPK & 5' Adenosine Monophosphate-activated Protein Kinase \\
\hline APAF-1 & Apoptotic Peptidase Activating Factor 1 \\
\hline BM & Basement Membrane \\
\hline CAFs & Cancer-Associated Fibroblasts \\
\hline CCNB1 & Cyclin B1 \\
\hline CD151 & Cluster of Differentiation 151 \\
\hline CDC & cell division cycle protein \\
\hline CDKN3 & Cyclin-dependent kinase inhibitor 3 \\
\hline COLs & Collagens \\
\hline CSCs & Cancer Stem Cells \\
\hline Cdk4 & cyclin-dependent kinase 4 \\
\hline ECM & Extra Cellular Matrix \\
\hline EGF & Epidermal Growth Factor \\
\hline EGFR & Epidermal Growth Factor Receptor \\
\hline EMT & Epithelial-Mesenchymal Transition \\
\hline ERK & Extracellular Signal-regulated Kinase \\
\hline FACITS & Fibril-Associated COLs with Interrupted Triple helices \\
\hline FAK & Focal Adhesion Kinase \\
\hline FBG & Fibrinogen-like Globe \\
\hline FBLN & Fibulin \\
\hline FGA2 & Fibrinogen Alpha chain isoform 2 \\
\hline FGF & Fibroblast Growth Factor \\
\hline FN & Fibronectin \\
\hline FOXA1 & Fork-head box protein A1 \\
\hline GFRs & Growth Factor Receptors \\
\hline GPC & Glypican \\
\hline Grb2 & Growth factor Receptor-Bound protein 2 \\
\hline HA & Hyaluronan \\
\hline HAS & Hyaluronan Synthases \\
\hline HB-EGF & Heparin-Binding EGF-like growth factor \\
\hline$H n f 4 \alpha$ & Hepatocyte Nuclear Factor $4 \alpha$ \\
\hline HSPG & Heparan Sulfate Proteoglycan \\
\hline IGF1R & Insulin-like Growth Factor 1 Receptor \\
\hline IL-1 $\beta$ & Interleukin-1 $\beta$ \\
\hline IL-6 & Interleukin 6 \\
\hline $\mathrm{IM}$ & Interstitial Matrix \\
\hline IMA & Invasive Mucinous Adenocarcinoma \\
\hline ITGB4 & Integrin Subunit Beta 4 \\
\hline JAK & Janus kinaes \\
\hline KRAS & Ki-ras2 Kirsten Rat Sarcoma viral oncogene homolog \\
\hline LPA & Lepidic Predominant Adenocarcinoma \\
\hline LCC & Large Cell Carcinoma \\
\hline
\end{tabular}

(Continued)
Continued

\begin{tabular}{|c|c|}
\hline LKB1 & Liver Kinase B1 \\
\hline IncRNA & Long noncoding RNA \\
\hline $\operatorname{Ln}$ & Laminins \\
\hline LOX & Lysyl Oxidases \\
\hline MACITs & Membrane-Anchored Collagens with Interrupted Triple helices \\
\hline MAD2L1 & Mitotic Arrest Deficient 2-Like Protein 1 \\
\hline MEK & MAPK Kinase \\
\hline MMPs & Matrix Metalloproteinases \\
\hline mTOR & Mammalian Target of Rapamycin \\
\hline MUCs & Mucins \\
\hline$N F-\kappa B$ & Nuclear Factor Kappa-light-chain-enhancer of activated B cells \\
\hline NID & Nidogen \\
\hline NSCLC & Non-small Cell Lung Cancer \\
\hline OSF-2 & Osteoblast-Specific Factor-2 \\
\hline PARP1 & Poly(ADP-Ribose) Polymerase 1 \\
\hline PDGF & Platelet-Derived Growth Factor \\
\hline PI3K & Phosphatidylinositol-3-Kinase \\
\hline PKB & Protein kinase B \\
\hline PLC- $\gamma$ & Phospholipase C-gamma \\
\hline PLOD2 & Procollagen-Lysine, 2-Oxoglutarate 5-Dioxygenase 2 \\
\hline Postn & Periostin \\
\hline PRC1 & Protein Regulator of cytokinesis 1 \\
\hline PTEN & Phosphatase and Tensin homolog \\
\hline PTPR $\zeta 1$ & Receptor-type Tyrosine-Protein phosphatase Zeta \\
\hline p130 Cas & p130 Crk-Associated Substrate \\
\hline p70s6K & $70 \mathrm{kDa}$ ribosomal protein S6 kinase \\
\hline Rac1 & Ras-related C3 botulinum toxin substrate 1 \\
\hline Rap1 & Ras-related protein 1 \\
\hline $\mathrm{ROBO} 2$ & Roundabout homolog 2 \\
\hline ROS1 & ROS proto-oncogene 1 \\
\hline RRM2 & Ribonucleoside-Diphosphate Reductase Subunit M2 \\
\hline RTKs & Receptor Tyrosine Kinases \\
\hline SCLC & Small Cell Lung Cancer \\
\hline SDC & Syndecan \\
\hline SLRP & Small Leucine-Rich Proteoglycans \\
\hline Sox2 & SRY-like HMG box \\
\hline SOS & Son of Sevenless \\
\hline Src & Sarcoma viral oncogene \\
\hline STAT & Signal Transducer and Activator of Transcription \\
\hline $\mathrm{SqCC}$ & Squamous Cell Carcinoma \\
\hline TCF4 & Transcription factor 4 \\
\hline TGF- $\beta$ & Transforming Growth Factor- $\beta$ \\
\hline TKls & Tyrosine Kinase Inhibitors \\
\hline $\mathrm{TN}-\mathrm{C}$ & Tenascin-C \\
\hline TLRs & Toll-like receptors \\
\hline TSP & Thrombospondin \\
\hline VTN & Vitronectin \\
\hline
\end{tabular}

